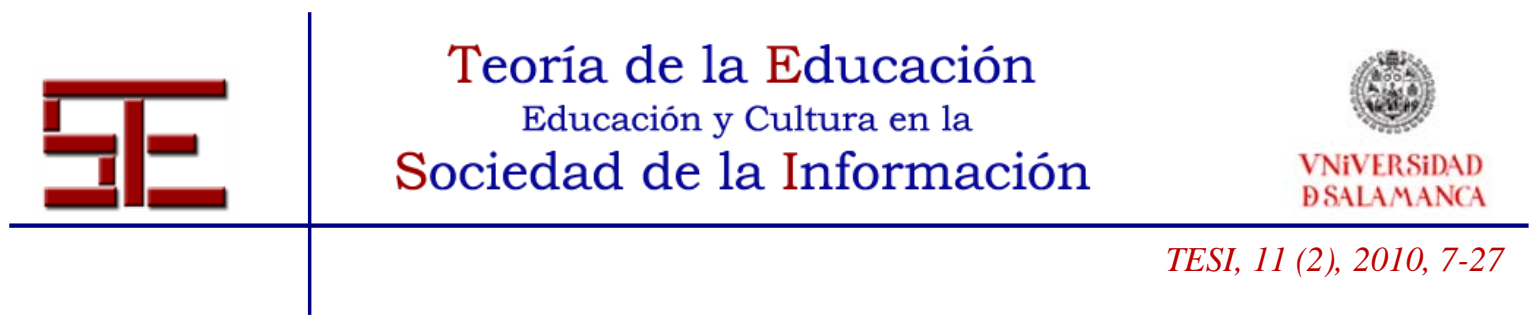

\title{
NUEVOS AVANCES EN LOS SISTEMAS DE VISUALIZACIÓN Y PRESENTACIÓN DE CONTENIDOS DOCENTES
}

Resumen:

Se presenta una visión general de los sistemas actuales de visualización y presentación de contenidos biomédicos, haciendo una reflexión sobre las nuevas tendencias tecnológicas a través de la imagen tridimensional. Se hace una valoración de las posibilidades didácticas que tienen estos recursos tecnológicos, en el proceso de formación en el campo de las ciencias de la salud.

Se describen en este artículo diferentes procedimientos como la holografia, la visualización estereoscópica, las técnicas de realidad virtual y aumentada para simulaciones de abordajes quirúrgicos.

Se describen las últimas tendencias en la visualización y estructuración del conocimiento a través de la generación de los denominados mapas conceptuales, los cuales permiten visualizar los contenidos docentes y sus relaciones jerárquicas.

Finalmente, se analiza el papel que juegan algunos dispositivos como las pizarras digitales, en los sistemas formativos de enseñanza, para la visualización interactiva de los contenidos docentes en el área de las ciencias biomédicas.

Palabras clave: Sistemas de visualización, formación biomédica, procedimientos tecnológicos, imagen tridimensional.

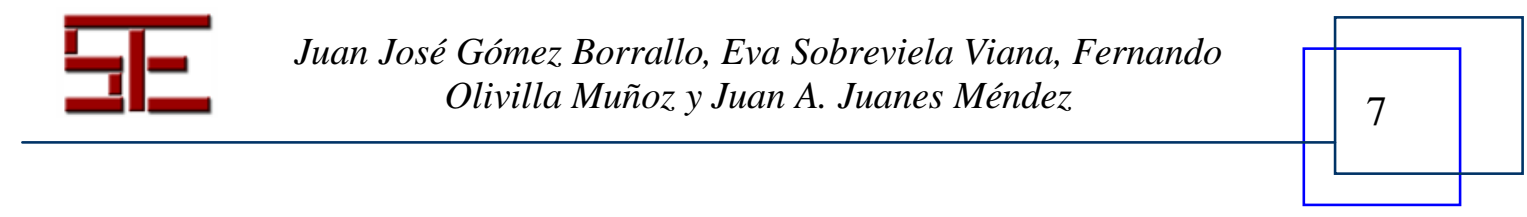




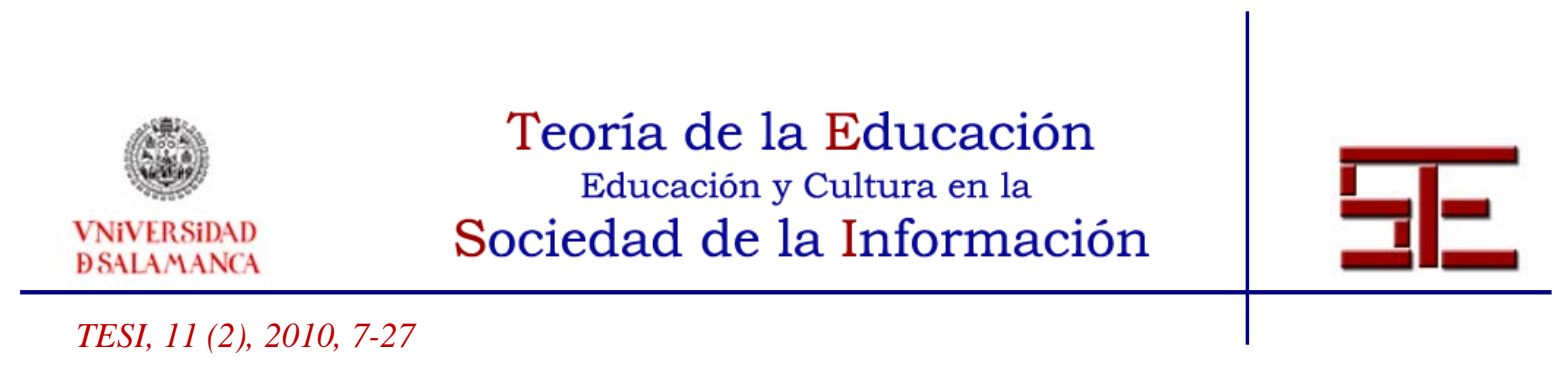

\section{NEW ADVANCES IN SYSTEMS FOR THE VISUALIZATION AND PRESENTATION OF TEACHING MATERIALS}

Summary:

We report a general view of current systems for the visualization and presentation of biomedical teaching materials, reflecting on the new technological trends using threedimensional imaging. As assessment is made of the didactic possibilities of such technological resources in the training process in the field of the health sciences.

Different procedures, such as holography, stereoscopic vision, and virtual reality and enhancement techniques for simulating surgical approaches are described.

An evaluation is made of the latest trends in the visualization and structuring of knowledge through the generation of the so-called conceptual maps, which allow teaching materials and their hierarchical relationships to be visualized.

Finally, an analysis is made of role played by some devices, such as digital blackboards in training systems for the interactive visualization of teaching materials in the field of the biomedical sciences.

Key words: Visualization systems, biomedical training, technological procedures, threedimensional image

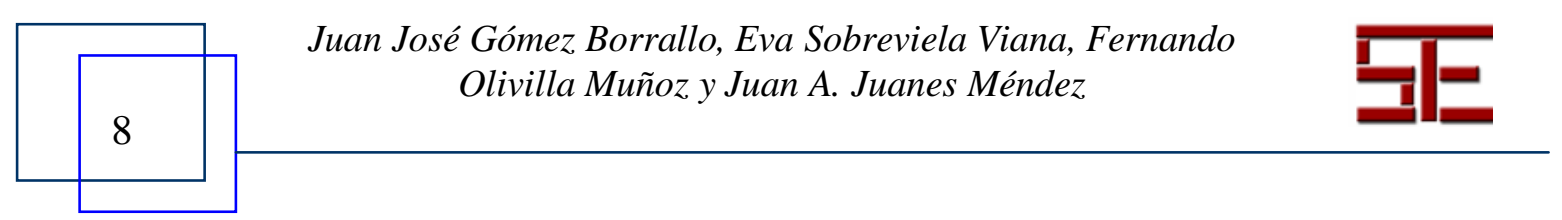




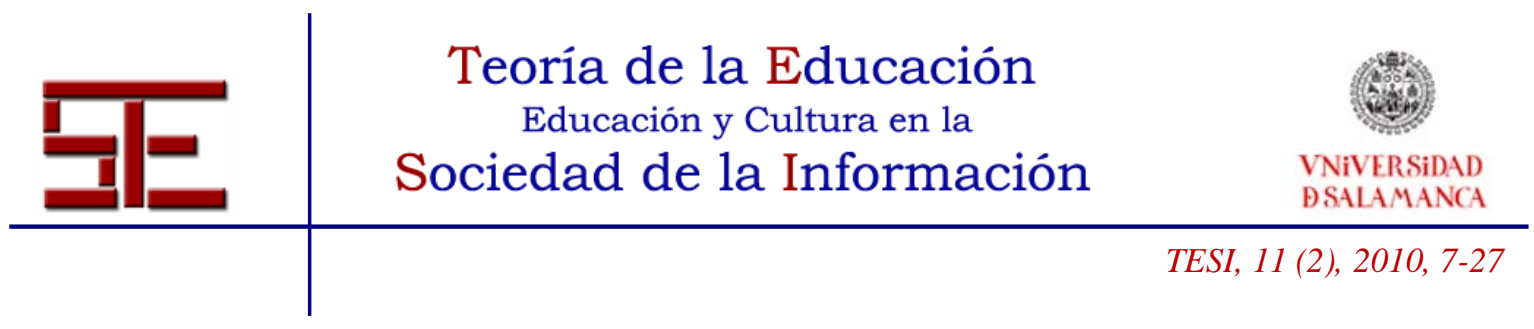

\title{
NUEVOS AVANCES EN LOS SISTEMAS DE VISUALIZACIÓN Y PRESENTACIÓN DE CONTENIDOS DOCENTES
}

Fecha de recepción: 02/09/2009; fecha de aceptación: 26/04/2010; fecha de publicación: 05/07/2010

\author{
Juan José Gómez Borrallo \\ juanjose@abadianet.com \\ Eva Sobreviela Viana \\ Fernando Olivilla Muñoz \\ Desarrollos Informáticos Abadia. Madrid \\ Juan A. Juanes Méndez \\ jajm@usal.es \\ Universidad de Salamanca
}

\section{1.- INTRODUCCIÓN}

Si hubiésemos de sintetizar la enorme variedad de pareceres y puntos de vista sobre la formación, respecto al objetivo de este trabajo, presentaríamos dos de carácter global. (i) El primero, considera que el proceso formativo tiene lugar en la mente del sujeto particular (estudiante) en relación con los objetos del mundo (materias), es la perspectiva piagetiana (J. Piaget, 1980). Dentro de él, las etapas, procesos y operaciones de incorporación de contenidos culturales que recorre la mente, son independientes de mediadores e instrumentos, de espacios culturales y de mediaciones comunicacionales. (ii) El segundo punto de vista, lo propuso L.S. Vygotskii (1979) proponiendo que el cambio del conocimiento tiene lugar en la ZDP (Zona de Desarrollo Potencial), la cual se describe como un espacio intersubjetivo mediado por instrumentos; la operación mental (proceso de formación) aparece dos veces: primero fuera, en la estructura intersubjetiva de la acción de formación y luego se incorpora significativamente a la estrucutura intersubjetiva. Desde esta perspectiva, son significativas las mediaciones instrumentales, desde el lenguaje oral y el texto escrito -instrumento de los instrumentos- a las mediaciones icónicas en cualquier formato.

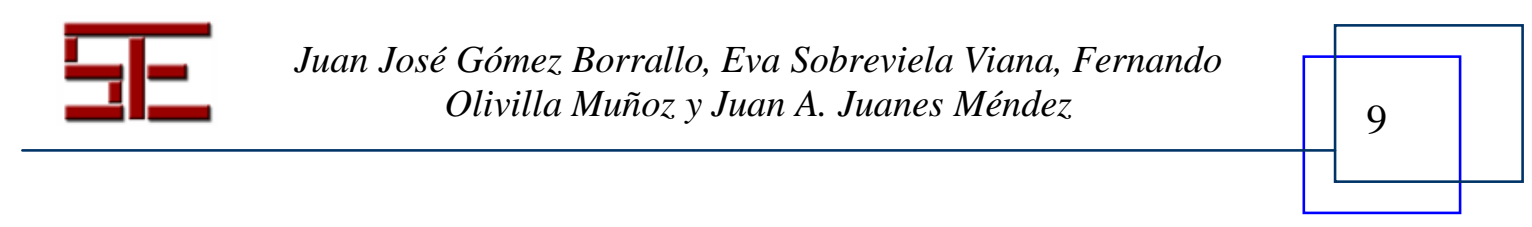




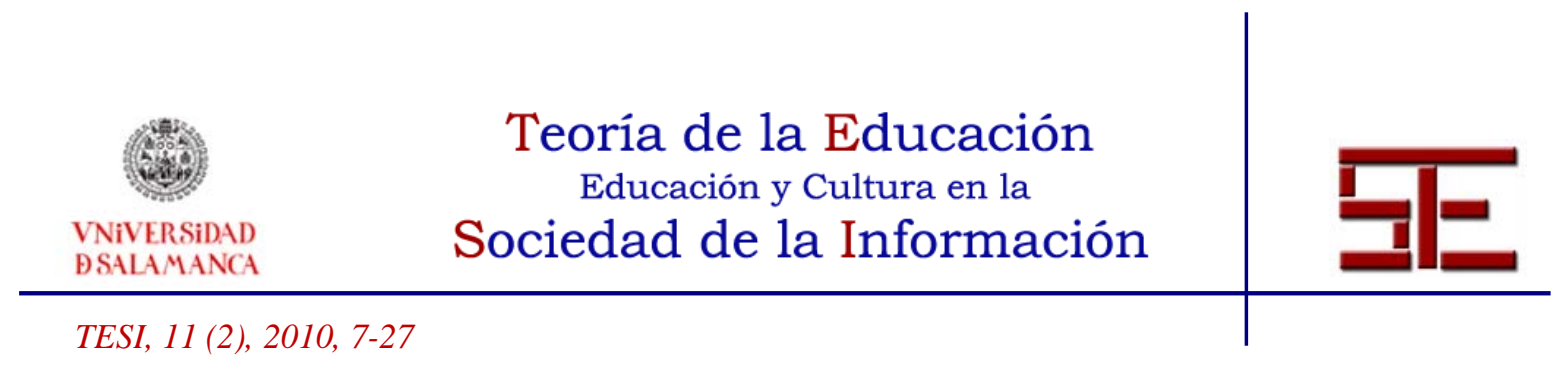

Las tecnologías informáticas proporcionan un abanico en desarrollo de instrumentos a incorporar a la ZDP, en los actos de formación, multiplicando las virtualidades posibles de las acciones de formación (M. Llamas-Nistal, 2003). Estas tecnologías presentan un especial interés especial en muchos campos de las Ciencias de la Salud, especialmente en el dominio del diagnóstico. Pero, es un hábito docente en este campo el empleo de imágenes en la actividad docente de calidad. Hoy, las aplicaciones digitales cada vez juegan un papel de mayor relevancia en todo el ámbito docente, como indicador del esfuerzo por la eficiencia pedagógica y la mejora de la calidad de los procesos formativos. Estos avances tecnológicos, han llevado consigo cambios en los sistemas de transmisión del conocimiento; en ellos, la imagen, en todos sus formatos, ha sido la gran protagonista.

En 2002, el Gobierno de Estados Unidos publicó el informe VISIONS 2020: Transforming Education and Training Through Advanced Technologies ${ }^{1}$, donde se analiza el posible recorrido de la educación hasta el 2020. Curiosamente, hace oficial un dato que muchos especialistas intuían hace tiempo: la tecnología va a sacudir la estructura de la práctica educativa hasta sus cimientos.

Desde hace 35.000 años (D. Lewis-Williams, 2005), la representación visual se convirtió en instrumento y procedimiento en los procesos de incorporación a la cultura. El concepto "bisonte" se plasma en un dibujo sobre una pared de piedra en la cueva de Altamira $^{2}$. Comprender la imagen es una forma de lectura que requiere de funciones mentales superiores y competencias cognitivas (J.J. Gibson, 1974).

Sin embargo, con la llegada de la alfabetización masiva, el peso específico de la actividad de conocimiento se desplaza hacia el texto escrito. Desde entonces, la imagen ha permanecido siempre en un segundo plano. Se redujo, para muchos, a mera ilustración o al ámbito genérico de la denominada "cultura visual”, donde se aparecen defensores tecnofantásticos como detractores tecnoapocalípticos (N. Mirzoeff, 2003). No obstante, es difícilmente discutible que en la Sociedad de la Información, que la imagen proporciona modelo y contexto imprescindible para la comprensión, como ya indicaba el informe VISIONS. La imagen, el sonido y el movimiento cada vez adquieren mayor relevancia respecto al objetivo de un aprendizaje significativo (R.E. Mayer, 2005). Es como si estuviésemos en una nueva era, una contingencia cultural de

\footnotetext{
${ }^{1}$ http://www2.ed.gov/about/offices/list/os/technology/plan/2004/site/documents/visions_20202.pdf 4-2010)

2 http://museodealtamira.mcu.es/ (19-4-2010)
}

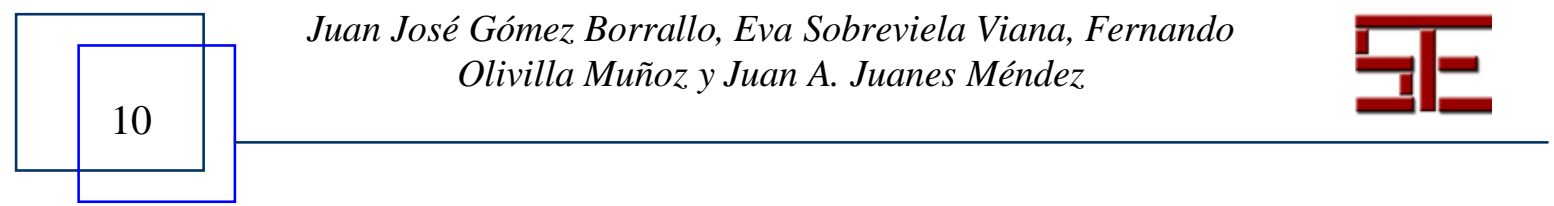




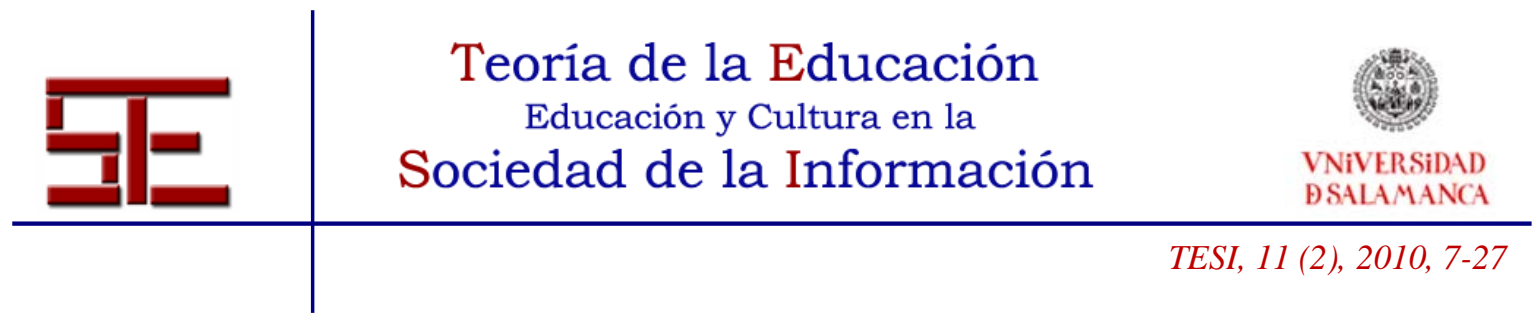

horizonte inabarcable, bajo entornos predominantemente visuales (Torres Ponjuan, 2008). La imagen pasa a ser un elemento imprescindible de los sistemas formativos en cualquier campo de las ciencias de la salud.

Presentaremos, en este artículo, una visión general de sistemas actuales de visualización y presentación de contenidos biomédicos, haciendo una reflexión sobre las nuevas tendencias tecnológicas a través de la imagen tridimensional. Además, llevaremos a cabo una valoración de las posibilidades didácticas que tienen, diferentes recursos tecnológicos, en el proceso de formación en distintos ámbitos de las ciencias de la salud.

\section{2.- SISTEMAS HOLOGRÁFICOS DE REPRESENTACIÓN DE IMÁGENES 3D}

El termino holograma, derivado de los términos griegos "holos" (todo) y "grama" (mensaje), fue acuñado en 1947, por el científico húngaro Dennis Gabor, el cual recibió por este hallazgo el Premio Nobel de Física en 1971, siendo el inventor de la holografía. Es una imagen registrada digitalmente, empleando una luz coherente de láser y permite guardar información tridimensional de un tema holografiado. Con una fuente única de luz blanca, la imagen se reproduce y aparece en tres dimensiones exactamente como se registró en el estudio, dentro o fuera de un soporte material (P. Martín Pascual, 1997). En realidad, un holograma contiene más información sobre la forma de un objeto que una fotografía simple, ya que permite visualizar su relieve. Además, variando la posición del observador se pueden obtener diferentes perspectivas del objeto holografiado (A. Beléndez, 2009).
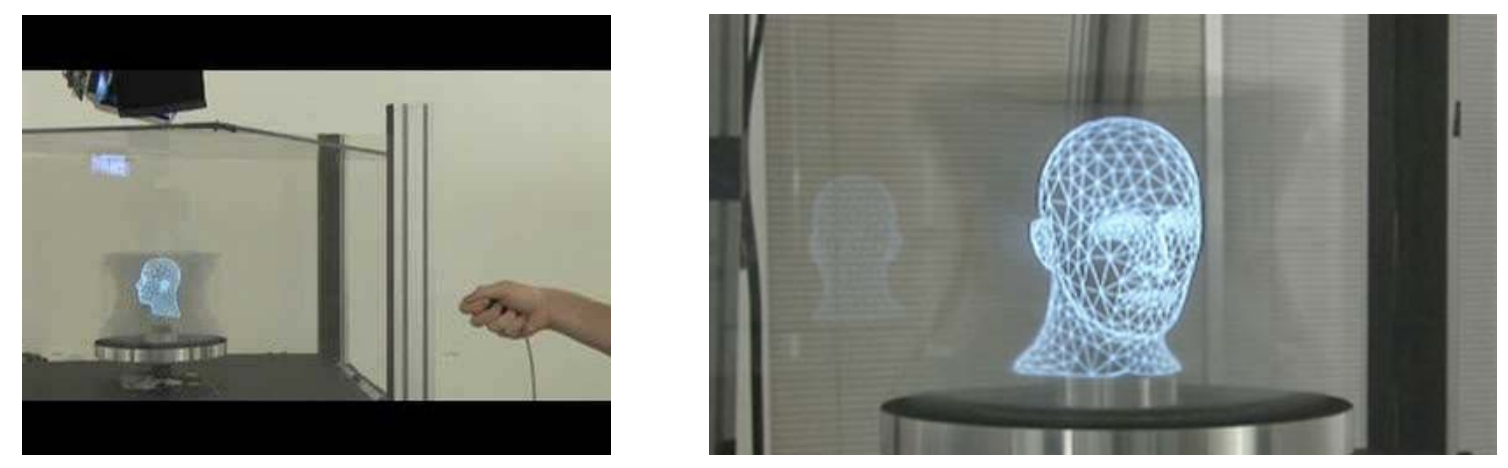

Fig. 1. Imagen holográfica de visualización 3D. Se pueden ver diferentes partes de la imagen dependiendo de la posición en que se mire el holograma. El usuario puede mirar por detrás del objeto al igual que lo hiciera como si este se encontrase ahí. Este holograma despliega una imagen tridimensional idéntica a un objeto sólido derivada de un modelo, escultura o de una imagen generada por computadora.

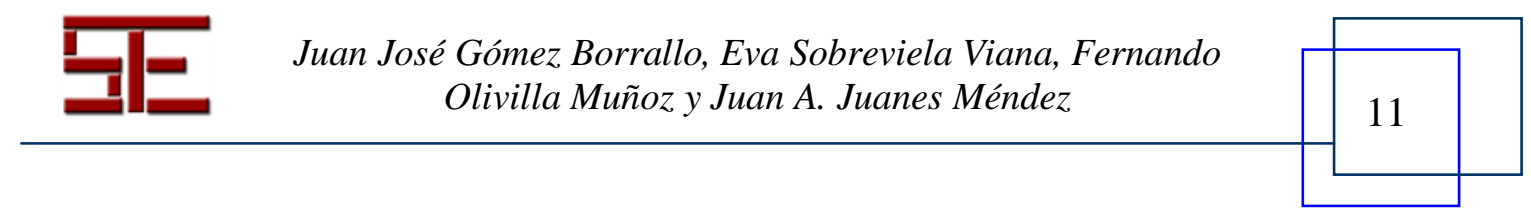




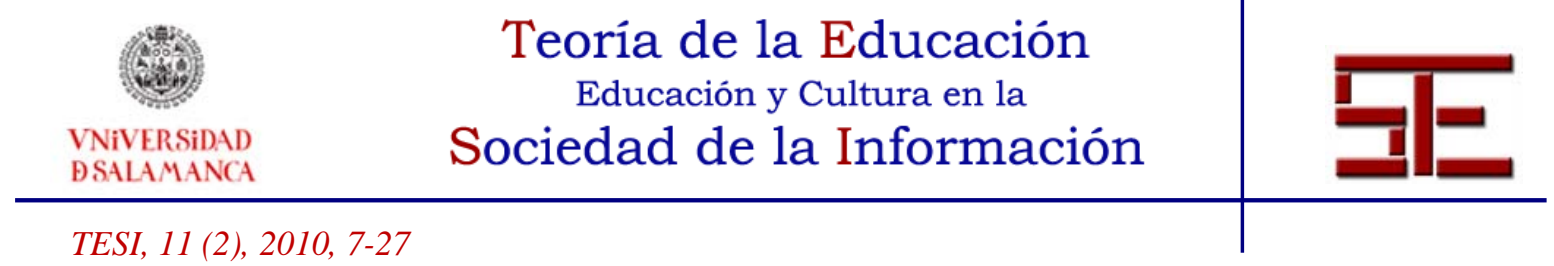

Con el surgimiento de los hologramas y su desarrollo posterior, se abrieron grandes posibilidades para su utilización como medio de enseñanza, por su característica de imagen tridimensional que constituye un duplicado óptico de un objeto. De esta forma, las técnicas holográficas aplicadas al campo de las ciencias de la salud, permiten acercarnos a la realidad de la visualización de objetos tridimensionales, estructuras anatómicas corporales, que se muestran frente a nosotros con una buena definición, en color y con posibilidad de movimiento (M.S. Hernández-Montes y otros,2004) (Fig. 1). Una de las aplicaciones con mayor aceptación de la holografía será como soporte de almacenamiento de información. Análogamente al DVD (Vídeo Disco Digital), en las técnicas de almacenamiento holográficas se emplean láseres que "transcriben" la información en un polímero fotosensible pero, a diferencia del DVD, en el que los datos se almacenan en la superficie, la holografía utiliza para ello todo el volumen del material de almacenamiento. Los laboratorios de investigación están perfeccionando sus polímeros especiales para adecuarlos a la producción de soportes de datos con capacidades de hasta 1.6 terabites (1.600 gigabites).

Este gigantesco volumen de datos, equivalente a 360 DVD actuales, corresponde a 780 millones de páginas DIN-A4 escritas, lo que equivale a los fondos de una gran biblioteca con unos cuatro millones de libros.

La Holografía constituye un poderoso instrumento al servicio del procesado de imágenes en general y de imágenes médicas o biológicas en particular, p.e., la detección de nódulos, con fronteras difusas o mal definidas, y para el análisis de muestras biológicas en tres dimensiones, posibilitando una visualización mejor definida de las estructuras. Se trata de una tecnología en desarrollo, que con toda probabilidad cambiará el formato de los recursos docentes para la modelización y representación de estructuras complejas en el futuro. Podría ejemplificarse la transformación del espacio de formación confrontando las representaciones en la pizarra y las presentaciones de documentos holográficos. (L. García Santiago, 2000). Se puede imaginar lo que sería un "libro de texto", cuando en el futuro se desarrollen las tecnologías holográficas y el libro fuera acompañado con el correspondiente soporte holográfico.

\section{3.- SISTEMAS DE VISUALIZACIÓN ESTEREOSCÓPICA}

La visión del hombre es binocular. Interpretamos la realidad a partir de dos imágenes con pequeñas diferencias entre sí, debido a la separación entre los ojos (A.M, Pons, 2004). La disparidad entre estas imágenes, aparentemente ínfima, es una de las formas que utiliza el cerebro para percibir la profundidad. En la base de cualquier tipo de percepción tridimensional, se encuentran una serie de complejos procesos fisiológicos y

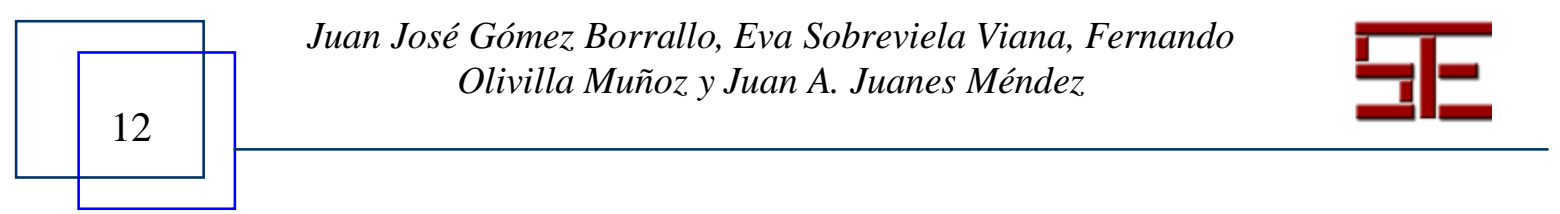




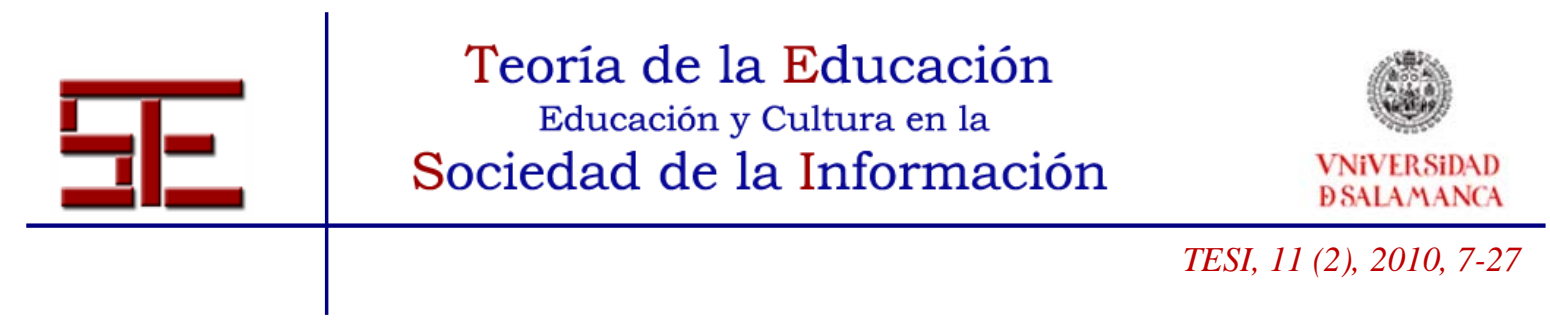

psicológicos relacionados con la visión, que desembocan en la creación de una sensación de volumen y dota a los objetos de un aspecto sólido y los sitúa en un punto concreto del espacio. Esta visión en tres dimensiones, corresponde a la denominada visión estereoscópica o visión en relieve, la cual resulta de la capacidad que tiene el sistema visual de dar aspecto tridimensional a los objetos a partir de las imágenes en dos dimensiones obtenidas en cada una de las retinas de los ojos. Este aspecto juega un papel primordial en el terreno docente de la imagen médica, al permitir con estas técnicas visualizar una estructura corporal con sensación tridimensional (Howard y Rogers, 1995).

El origen de las técnicas estereoscópicas se remonta al siglo XIX, con la invención del estereoscopio de Charles Wheatstone y, posteriormente, la primera cámara fotográfica estereoscópica. Esta cámara obtenía dos imágenes de cada fotografía, que posteriormente podían verse en relieve mediante un visor especial (Lipton, 1997).

En los años 50, la década dorada del cine, aparecieron las primeras películas en tres dimensiones, lamentablemente con escaso éxito. La técnica aún era incipiente y ocasionaban molestias visuales, lo que hizo que el público rechazara este formato. No sería hasta los años 80, tras grandes inversiones en investigación y medios, cuando se conseguirían los resultados más espectaculares, con los sistemas de gran formato de película como el IMAX, con imágenes de alta resolución en pantallas gigantescas. A partir de entonces, con las dificultades más o menos solucionadas.

Las ciencias de la salud han resultado especialmente receptivas a los nuevos hallazgos tecnológicos. La visualización estereoscópica tiene evidentes aplicaciones en la creación de programas multimedia de anatomía virtual, la interpretación de imágenes para el diagnóstico o como ayuda en las intervenciones quirúrgicas.

Es posible visualizar imágenes o modelos del interior del cuerpo humano (Fig. 2), bien artificiales, bien generados a partir de imágenes reales obtenidas por medio de técnicas de diagnóstico por imagen como la Tomografía Computarizada (TC) o la Resonancia Magnética (RM).

Los sistemas de visión estereoscópica ofrecen al usuario distintas utilidades como representación de información gráfica compleja, la telepresencia o el entrenamiento de la percepción espacial.

La visión estereoscópica permite interpretar el entorno tridimensional que le rodea; sin embargo, la utilización de estos sistemas en la didáctica exige un conocimiento de sus posibilidades y limitaciones. Por ello, el docente debe elegir el sistema más adecuado

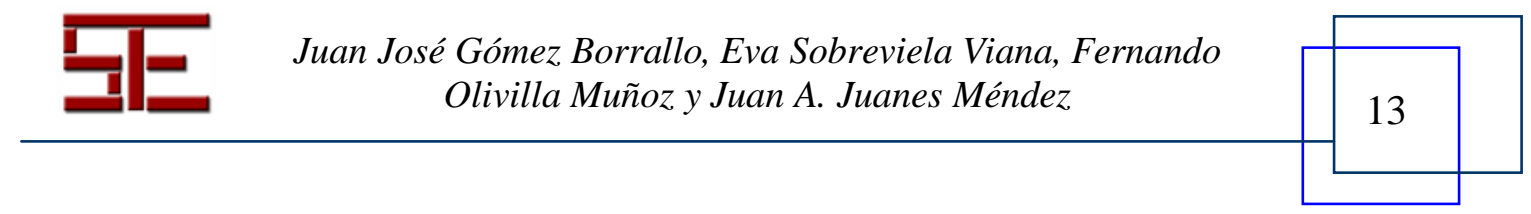




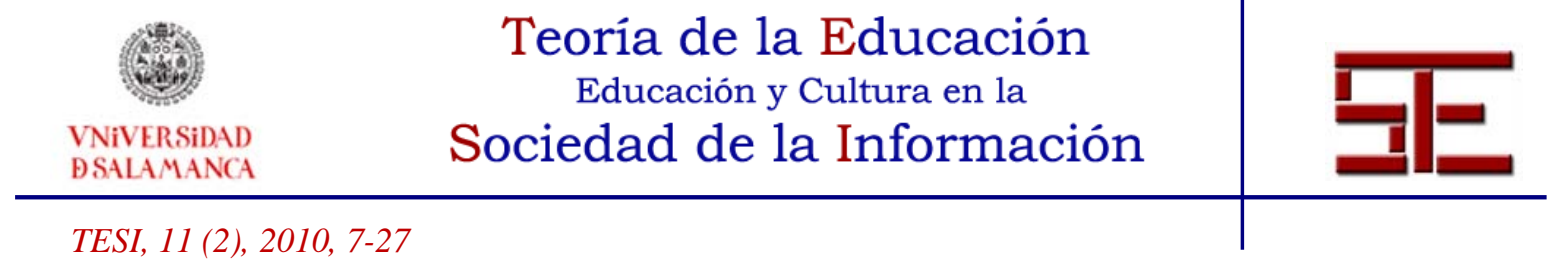

para cada método de transmisión de conocimientos, bien sea la clase magistral o las prácticas. Deberemos tener siempre presente que no todos los alumnos tendrán la capacidad de visión en estéreo. Las materias en que esta tecnología resulta de utilidad son muchas y diversas en cualquier área de las ciencias de la salud.

El objetivo final del manejo de estos procedimientos tecnológicos, es buscar la motivación de las nuevas generaciones de estudiantes, intentando mantener su capacidad de atención.

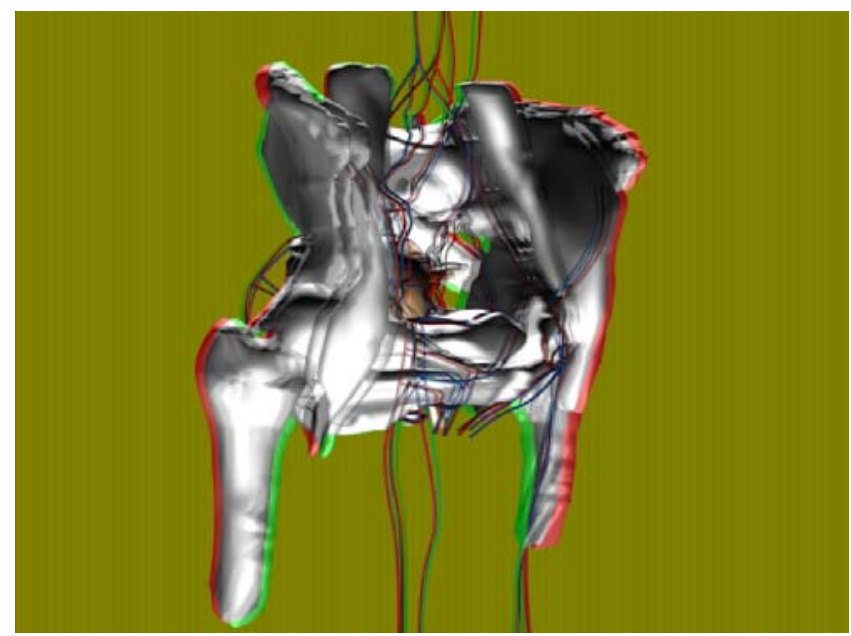

Fig. 2.- Imagen de la pelvis, desarrollada en nuestro departamento de sistemas visuales, generada para entornos estereoscópicos. Se trata de un estado de visión que se produce cuando ambos ojos fijan su atención simultáneamente sobre el mismo objeto. La fusión automática de las imágenes crea una percepción única en la que es posible apreciar distancias, espesores, profundidades y dimensiones.

La creación de imágenes tridimensionales mediante computador (B. Cyganek, 2009) (Ch. Wölhler, 2009) (G. Pajares, 2007) adquiere una nueva dimensión cuando se combina con las técnicas estereoscópicas; de esta forma nos adentramos en nuevo entorno tecnológico conocido como Realidad Virtual y su extensión hacia la realidad aumentada..

\section{4.- SISTEMAS DE REALIDAD VIRTUAL Y REALIDAD AUMENTADA}

El término realidad virtual (RV) es en sí mismo paradójico ya que se compone de dos conceptos semánticamente opuestos. Se trata de un sistema tecnológico cuyo objetivo es crear una realidad aparente que permita al usuario tener la sensación de formar parte de ella o de quedar implicado en su contexto. Estos “entornos virtuales” constituyen un

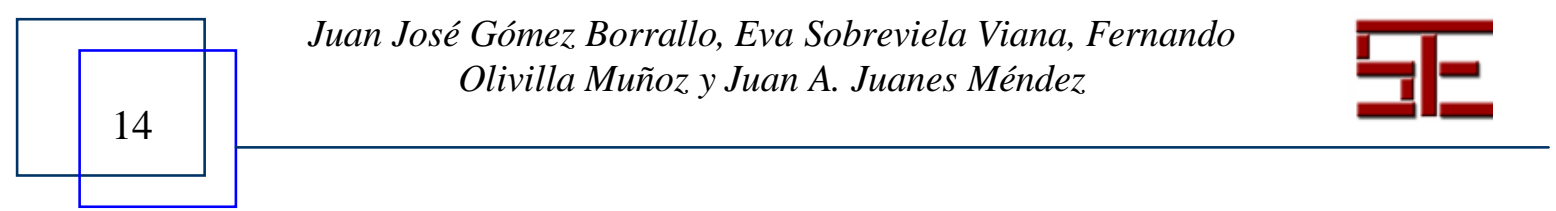




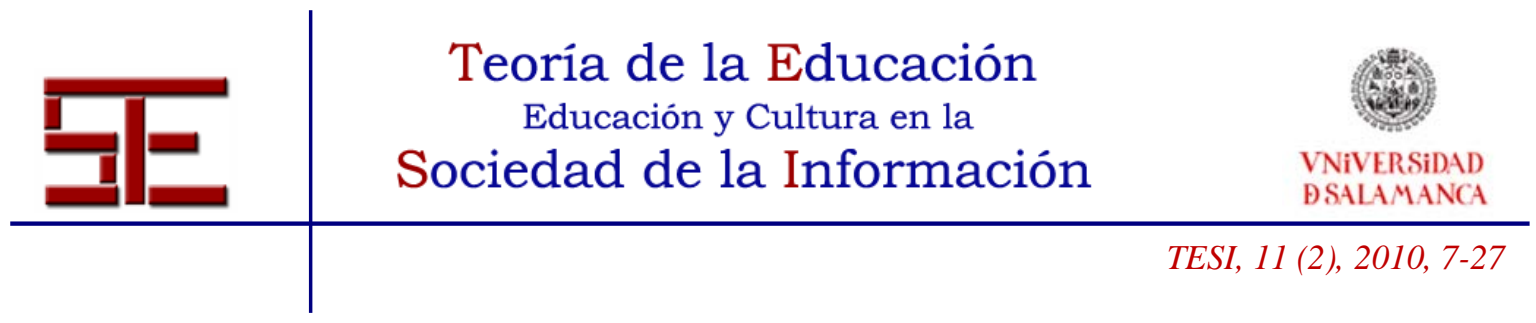

modelo matemático que describe un espacio tridimensional dentro del cual existen objetos con los que se puede interactuar (Fig. 3)

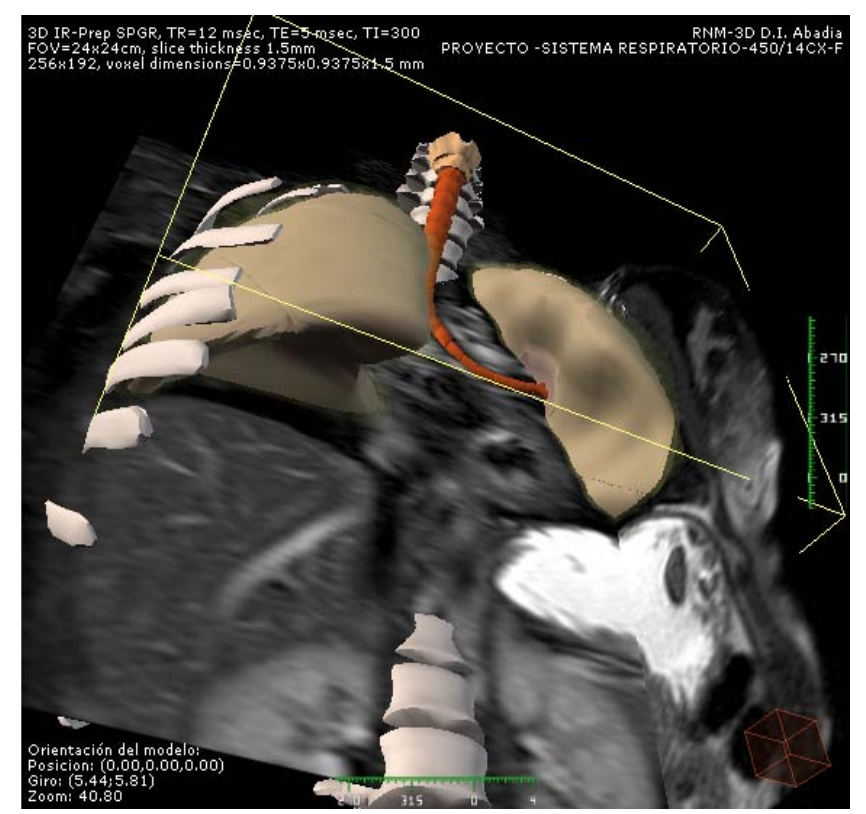

Figura 3.- Imagen tridimensional del aparato respiratorio, generada por nuestro grupo de trabajo, a partir de secciones seriadas de Resonancia Magnética. El usuario puede interactuar libremente con cada una de las estructuras anatómicas que constituyen el aparato respiratorio, pudiendolas visualizar en cualquier posición espacial.

Por tanto, estos sistemas tecnológicos proporcionan una visualización participativa del usuario, en tres dimensiones, y la simulación de mundos virtuales, lo que ofrece al sujeto la posibilidad de experimentar determinados ambientes como si se encontrase en dentro de ellos (Parra et al., 2001).

Esto se consigue mediante la generación, por ordenador, de un conjunto de imágenes que son contempladas por el usuario a través de un casco, provisto de un visor especial. Algunos equipos se completan con trajes y guantes, equipados con sensores diseñados para simular la percepción de diferentes estímulos, que intensifican la sensación de realidad. Los programas de software para el desarrollo de aplicaciones de RV se fundamentan en los conceptos de computación gráfica.

Su aplicación, aunque centrada inicialmente en el terreno de los videojuegos, como casi todo de un tiempo a esta parte, se ha extendido a otros muchos campos como el educativo biosanitario, existiendo desarrollos muy interesantes. Los usos de la realidad

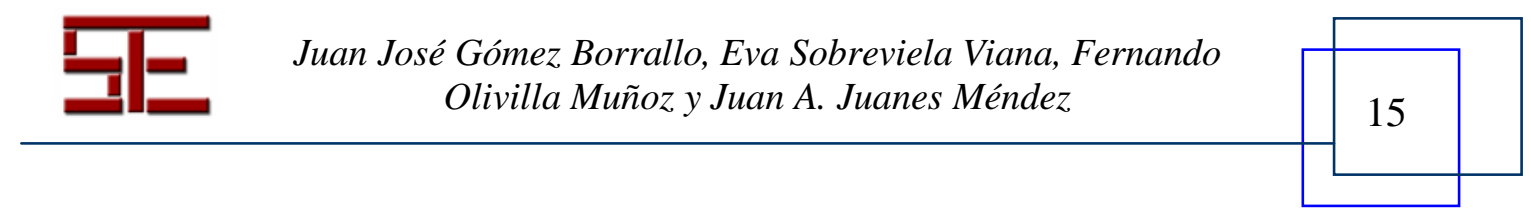




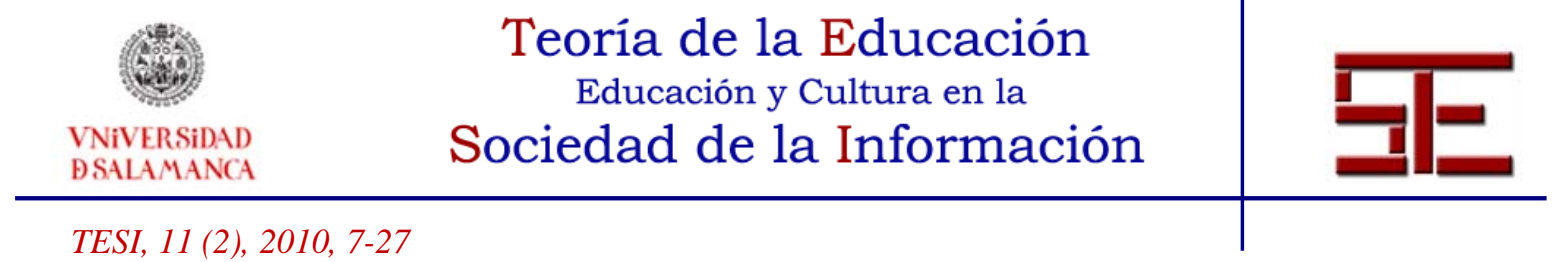

virtual en medicina pueden ser muchos, y de hecho es uno de los campos que se ha aprovechado más de los avances de la realidad virtual.

Actualmente los campos más importantes de aplicación son los simuladores para formación y entrenamiento en tareas sofisticadas, permitiendo al facultativo o al estudiante de medicina experimentar las sensaciones reales para desarrollar habilidad y destreza frente a técnicas complicadas, como son los cateterismos o la realización de endoscopias. También se ha utilizado estas procedimientos tecnológicos para el tratamiento de enfermos de fobias y otros traumas (acrofobia, claustrofobia, etc...), y sobre todo, en los últimos años, en la cirugía.

Los simuladores de abordajes quirúrgicos, basados en técnicas de RV, resultan muy adecuados para adquirir conocimientos y valorar las diferentes situaciones que se puedan plantear en una intervención antes de desarrollarla sobre un paciente real. Por tanto, los simuladores quirúrgicos abren la posibilidad a los cirujanos de ensayar operaciones complicadas antes de realizarlas realmente, reduciendo así los riesgos derivados de la intervención (Fig. 4).

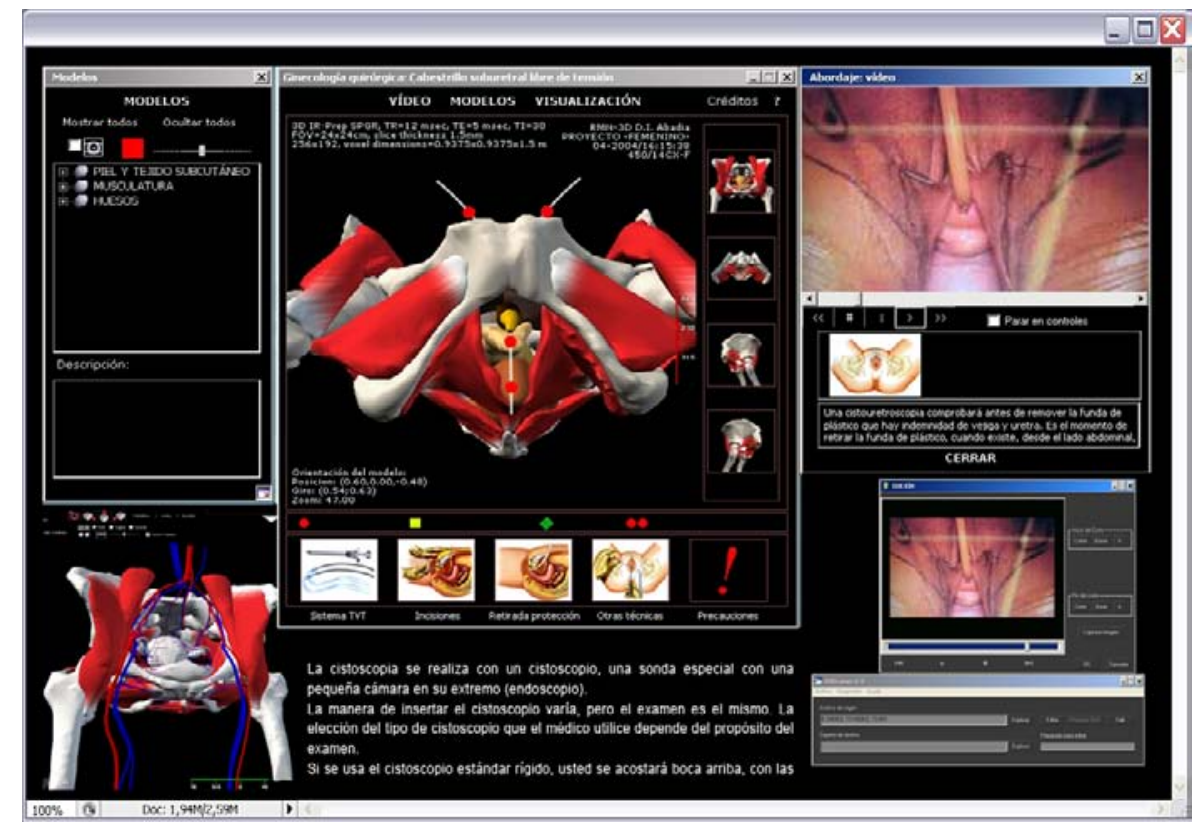

Figura 4.- Proyecto de reconstrucción georeferenciada para simulador quirúrgico en colocación de mallas. Visualización del la interfaz de usuario. El desarrollo combina imágenes reales de abordajes quirúrgicos, con imágenes de las estructuras anatómicas, reconstruidas en $3 D$, a partir de secciones de resonancia magnética.

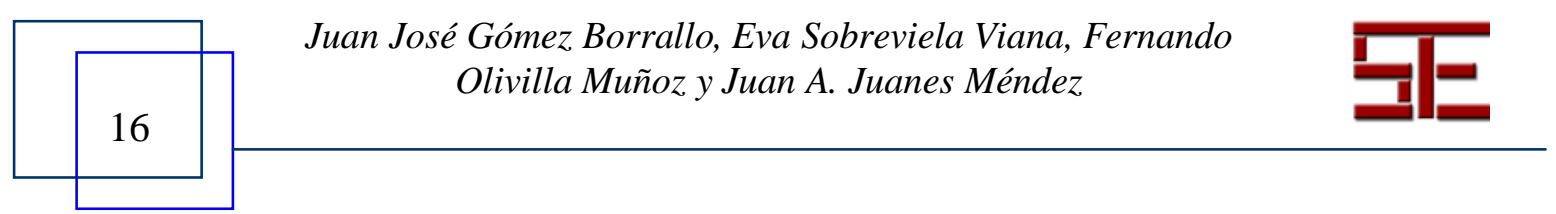




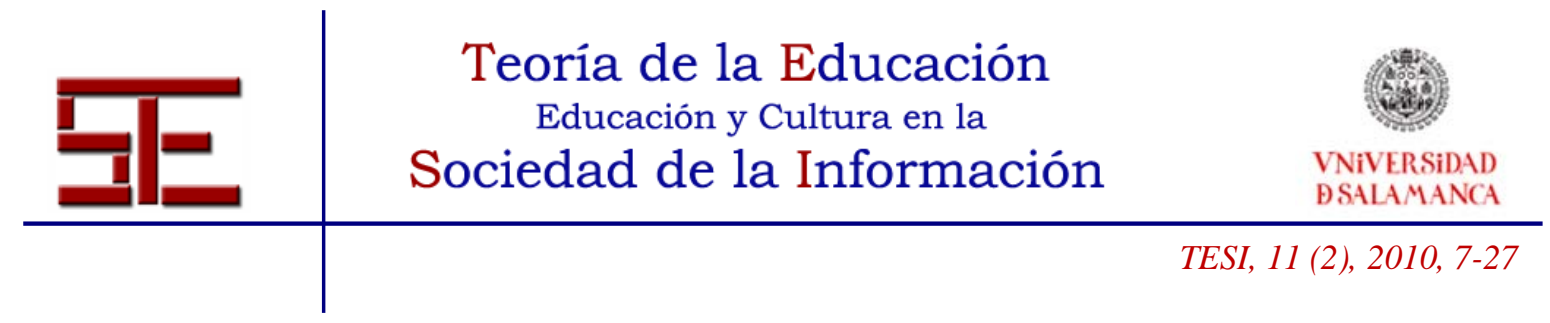

Existen aplicaciones que permiten realizar tareas de microcirugía a través de un robot trasladando y aumentando las sensaciones que el robot experimenta a un sistema de realimentación táctil que maneja el cirujano. Otra aplicación es en la cirugía mínimamente invasiva, ya que permite guiar y manipular las distintas herramientas que se utilizan para mejorar la intervención. La evolución de las técnicas de imagen médica también ha constituido un nuevo tipo de cirugía guiada mediante imágenes previamente obtenidas y en las que se identifican los objetivos de la intervención claramente.

La realidad virtual puede ser de dos tipos: inmersiva y no inmersiva. Los métodos inmersivos de realidad virtual se ligan a una serie de dispositivos que capturan los movimientos de las distintas partes del cuerpo. La realidad virtual no inmersiva no necesita dispositivos adicionales al ordenador, por lo que presenta varias ventajas, como su bajo coste y la facilidad de manejo.

No cabe duda, por tanto, que, la formación y educación en ciencias de la salud puede ser uno de los ámbitos más beneficiados por herramientas de realidad virtual en todos los campos de la formación académica. Sin embargo hasta el momento estas tecnologías aún no están muy incorporadas a los centros docentes universitarios y hospitalarios.

Por otra parte, la realidad aumentada $(\mathrm{RA})^{3}$ es el término empleado para definir una visión directa o indirecta de un entorno físico en el mundo real, cuyos elementos se combinan con elementos virtuales para la creación de una realidad mixta a tiempo real. Por tanto, RA constituye una extensión de la realidad virtual, siendo uno de los campos actuales de mayor investigación en tecnologías avanzadas en medicina. Consiste en un conjunto de dispositivos que añaden información virtual a la información física ya existente. Esta es la principal diferencia con la realidad virtual, puesto que no sustituye la realidad física, sino que sobreimprime los datos informáticos al mundo real. Con la ayuda de la tecnología (por ejemplo, añadiendo la visión por Ordenador y reconocimiento de objetos) la información sobre el mundo real alrededor del usuario se convierte en interactiva y digital. La información artificial sobre el medio ambiente y los objetos, puede ser almacenada y recuperada como una capa de información en la parte superior de la visión del mundo real.

La realidad aumentada explora la aplicación de imágenes generadas por ordenador, en tiempo real, a secuencias de vídeo como una forma de ampliar el mundo real. La

3 Mireia Ribera Turró (2005): Evolución y tendencias en la interacción persona-ordenador http://www.elprofesionaldelainformacion.com/contenidos/2005/noviembre/3.pdf (15-4-2010)

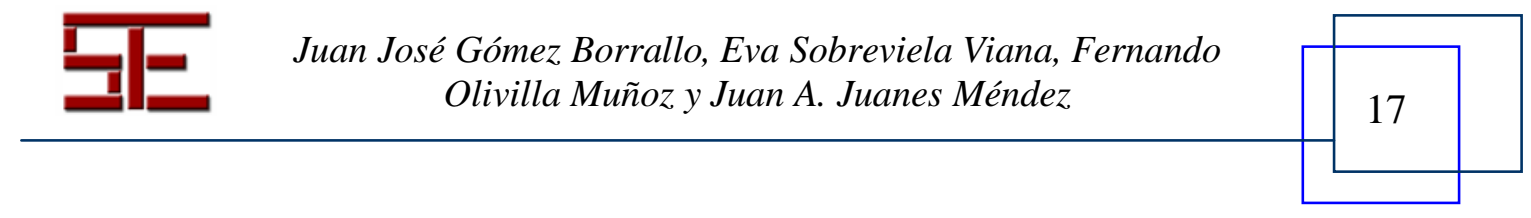




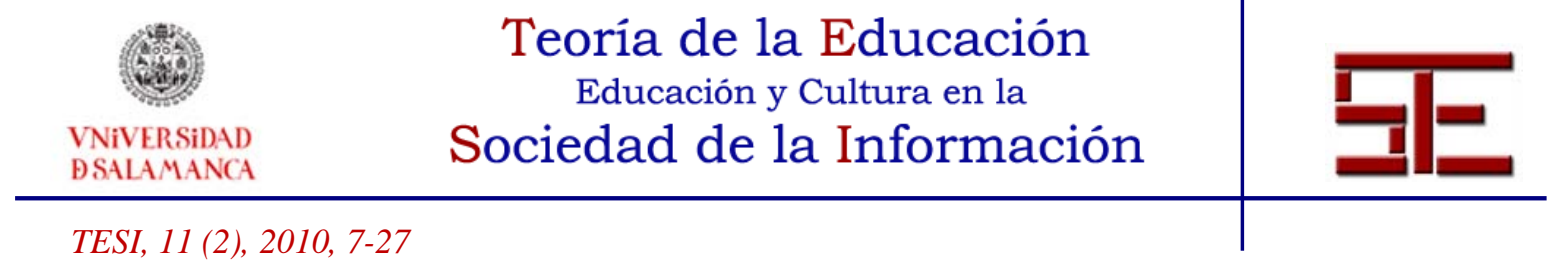

investigación incluye el uso de pantallas colocadas en la cabeza, un display virtual colocado en la retina para mejorar la visualización, y la construcción de ambientes controlados a partir sensores y actuadores.

La RA es un campo de investigación reciente ${ }^{4}$, debido a que hace tan sólo unos años las capacidades de los sistemas de procesamiento de imagen digital, gráficos por ordenador y nuevas tecnologías de visualización han permitido abordar los problemas planteados por la RA. Nuestro grupo de trabajo ha llevado a cabo experiencias con esta tecnología, como la que se observa en la figura 5., generando un sistema para la navegación 3D, asistida por ordenador, para intervenciones de Neurocirugía.

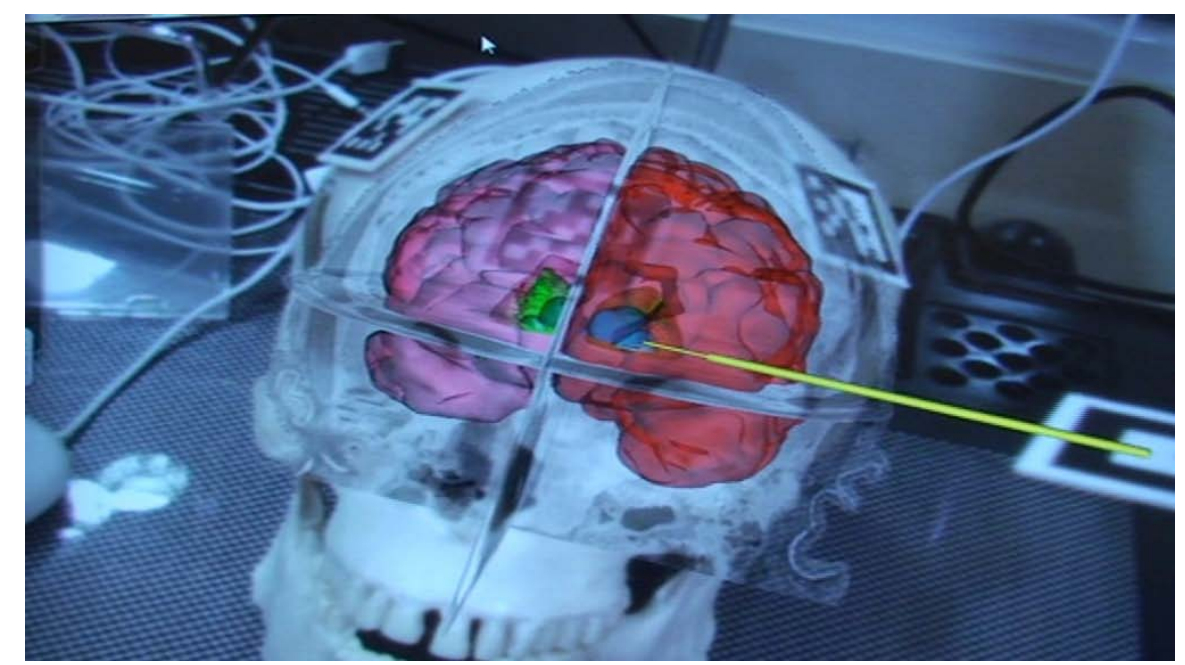

Figura 5- Visualización de un entorno virtual de realidad aumentada. El sistema permite obtener la superposición de estructuras anatómicas sobre la imagen del paciente, o sobre un cráneo, visualizando un entorno virtual cercano a la realidad. La alineación de forma rápida y precisa, de la imagen real con una imagen visual de las estructuras cerebrales internas, dentro de la misma escena, le da una apariencia real.

La RA se ha convertido en un campo de investigación preferencial para nuestro grupo de investigación y trabajo, estando interesados en desarrollar sistemas de visualización interactiva avanzada.

4 X. Basogain y otros: Realidad Aumentada en la Educación: una tecnología emergente. http://anobium.es/docs/gc_fichas/doc/6CFJNSalrt.pdf (10-3-2010)

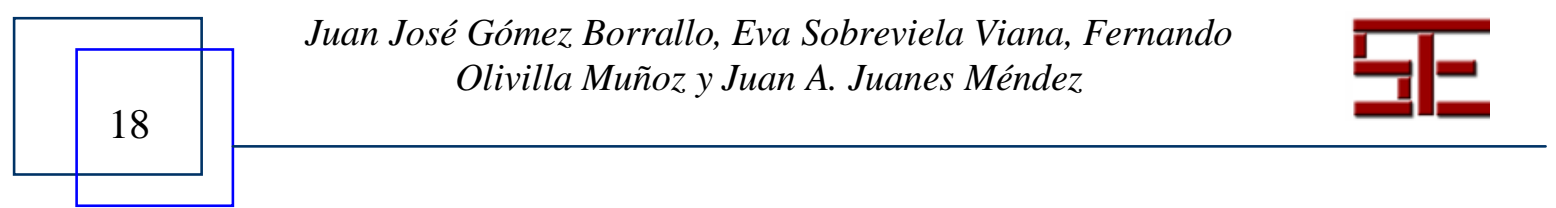




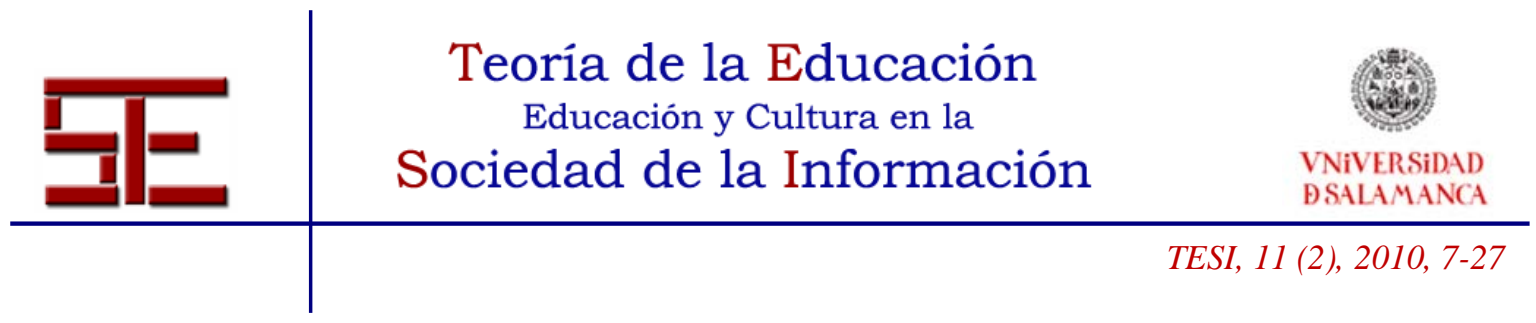

Un sistema de RA genera una vista compuesta para el usuario. Es una combinación de la escena verdadera inspeccionada por el usuario y una escena virtual generada por ordenador que mejora (aumenta) la escena con la información adicional. El fin último de la RA es crear un sistema tal, que el usuario casi no pueda apreciar la diferencia entre el mundo verdadero y el aumentado virtual. Al usuario de este sistema definitivo le parecería que está mirando a una escena verdadera única. Sobre este objetivo es a lo que muchos grupos de investigación estamos dedicándole bastante tiempo. Las técnicas de visión empleadas en RA deben ser capaces de alinear de forma rápida y precisa una imagen real con una imagen visual de la misma escena. La habilidad para ejecutar dicha operación es fundamental en RA.

\section{5.- MAPAS CONCEPTUALES}

Hemos hablado hasta el momento de nuevas formas de presentar la información. Sin embargo, esta visión y estructuración del conocimiento, que presentamos en este apartado, no sólo cambiará la forma de visualización sino también el fondo. El modo de estructurar el conocimiento será un punto a replantear en un futuro inmediato. Los mapas conceptuales podrían tomarse como un procedimiento para visualizar la estructura sistemática de un contenido de conocimiento ${ }^{5}$.

No hay visualización eficaz sin un proceso previo. La presentación de la información docente también está cambiando. Se adapta a los nuevos tiempos, se sublima, se condensa.

En este sentido, los mapas conceptuales o mapas de conceptos son un buen medio para visualizar ideas o conceptos y sus relaciones jerárquicas (Fig. 6). Los mapas conceptuales, son una técnica que cada día se empieza a utilizar más en los diferentes niveles educativos, como herramienta para el aprendizaje, ya que permite al docente ir construyendo el proceso de enseñanza con sus alumnos o estudiantes y explorar con ellos los conocimientos previos; de esta forma el alumno podrá organizar, interrelacionar y fijar el conocimiento del contenido estudiado o analizado (Ontaria, 1994; Fonseca et al., 2004).

El desarrollo, en los últimos años, de los mapas conceptuales y su aplicación a distintas áreas de conocimiento, ha abierto un camino de integración de los distintos elementos

\footnotetext{
${ }^{5}$ A. M. Costamagna (2001): Los mapas conceptuales como expresión de procesos de interrelación para evaluar la evolución del conocimiento de alumnos universitarios.

http://ddd.uab.es/pub/edlc/02124521v19n2p309.pdf (23-3- 2010)
}

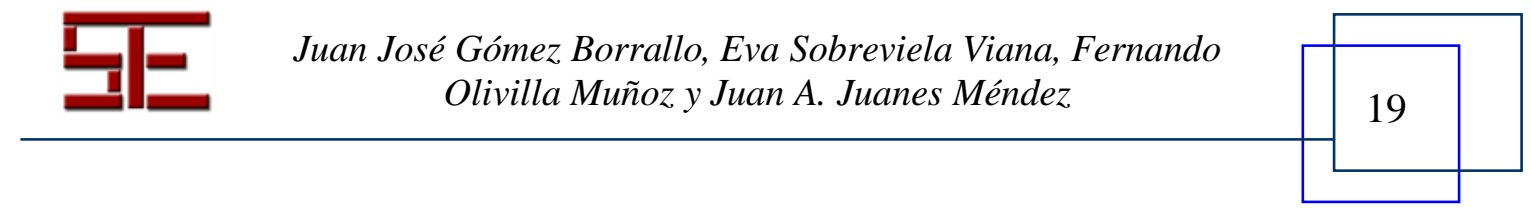




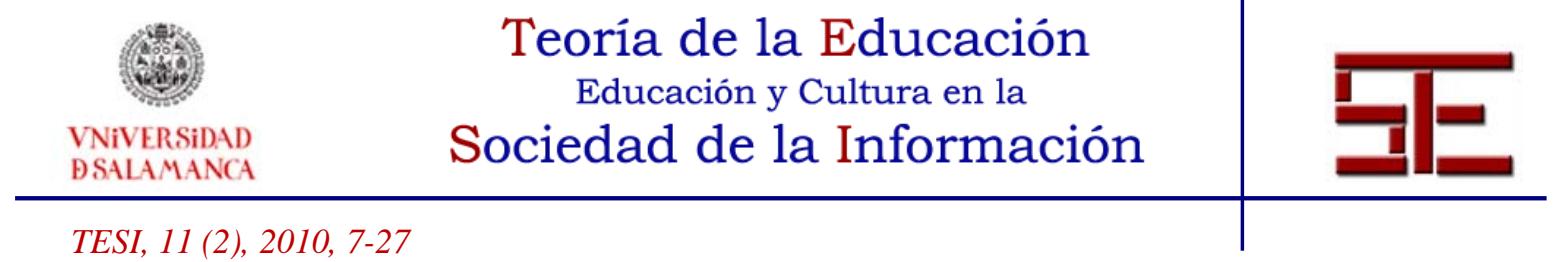

que constituyen el proceso enseñanza-aprendizaje, consiguiendo importantes logros que han permitido alcanzar muchos de los objetivos educativos con mayor facilidad. Estos mapas, son una representación bidimensional de un conjunto de conceptos y de las relaciones que dichos conceptos mantienen entre si. Se trata, por tanto de un recurso docente esquemático, formado por un conjunto de significados conceptuales incluidos en una estructura organizada.

Con la elaboración de estos mapas se aprovecha la gran capacidad humana para reconocer pautas en las imágenes visuales, con lo que se facilitan el aprendizaje y el recuerdo de lo aprendido (Sánchez Quevedo, 2005).

Desde el punto de vista docente, los mapas conceptuales permiten al estudiante:

- La organización lógica y estructurada de los contenidos docentes de aprendizaje, ya que son útiles para seleccionar, extraer y separar la información significativa o importante de la información superficial.

- Integrar la información de los contenidos docentes, estableciendo relaciones de subordinación e interrelación.

- Desarrollar ideas y conceptos a través de un aprendizaje interrelacionado.

- Insertar nuevos conceptos en la propia estructura de conocimiento.

- Organizar el pensamiento

- Expresar el propio conocimiento actual acerca de un tema concreto

- Organizar el material de estudio.

- Utilizar imágenes que permiten la fijación de conocimientos en la memoria del usuario, ya que la capacidad de retener ideas es mayor a través del recuerdo de imágenes (Figs. 6 y 8).

Cada uno de los nodos del mapa conceptual, ya sea textual o iconográfico contienen un concepto, un ítem o una cuestión. El mapa conceptual es un instrumento útil para la organización y la representación visual del conocimiento, cuya elaboración puede ejecutar el docente para mostrar al discente como se relacionan determinados conceptos, con el objetivo de alcanzar una mayor comprensión de los conceptos que estudia (Ontaria, 1994).

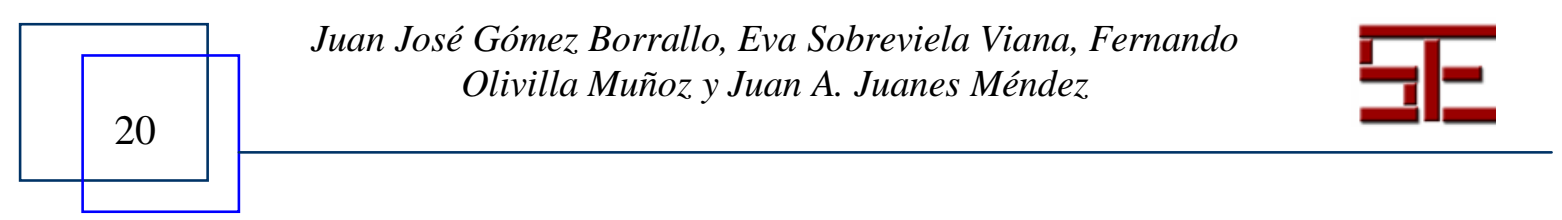



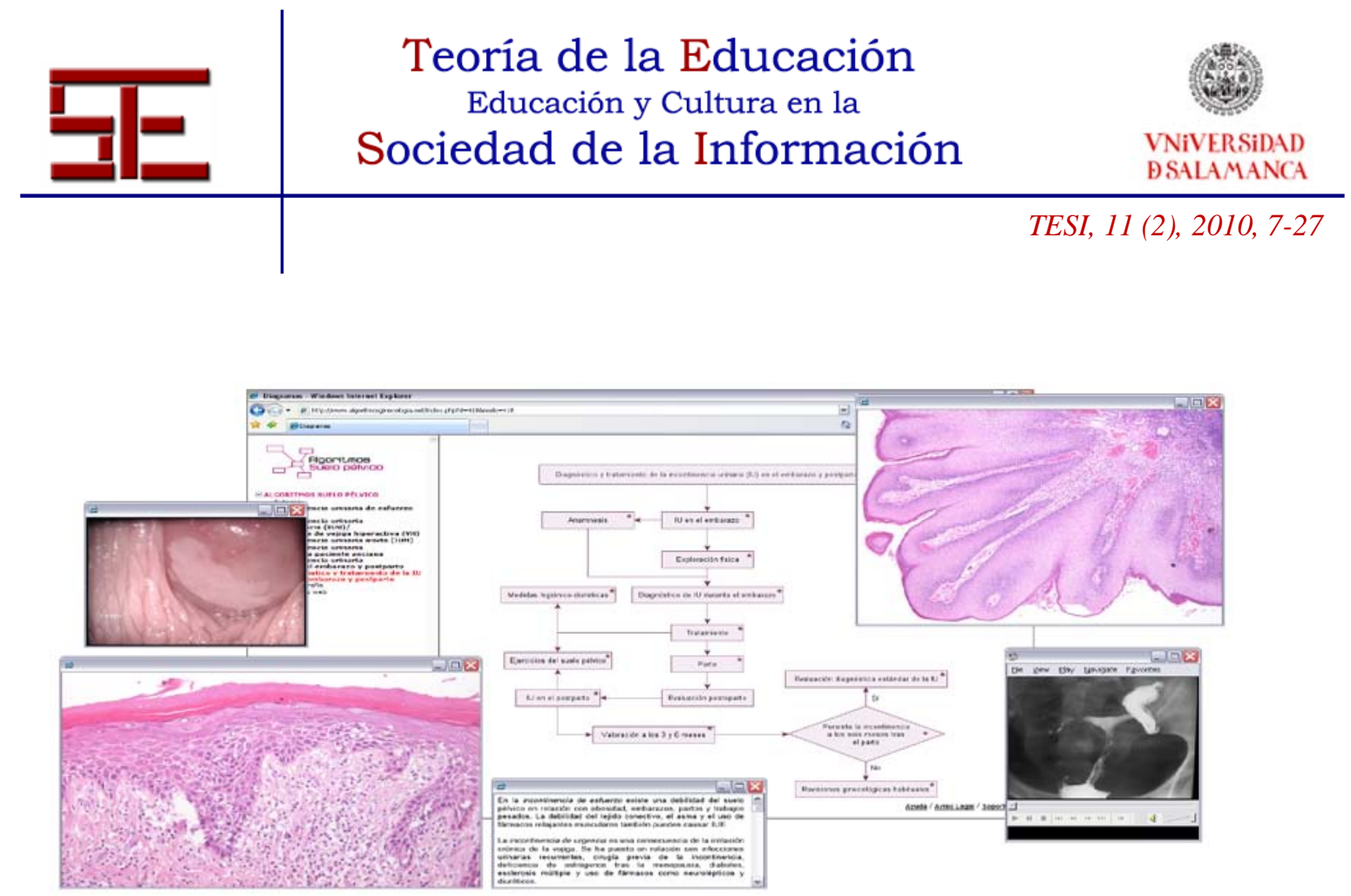

Figura 6.- Sistema de visualización de la información, mediante interfaces que manejan algoritmos de documentación visible y comprensible a través de mapas conceptuales más atractivos, que permiten acceder a las bases de datos con más libertad que la disciplina lineal o arbórea que tradicionalmente se propone; dando la oportunidad de observar y valorar las relaciones que se establecen entre las distintas partes.

Los mapas conceptuales pueden construirse de muy diversas maneras, diferenciándose entre si, por el formato con el que se representa la información (Figs. 6, 7 y 8).

Juan José Gómez Borrallo, Eva Sobreviela Viana, Fernando Olivilla Muñoz y Juan A. Juanes Méndez 


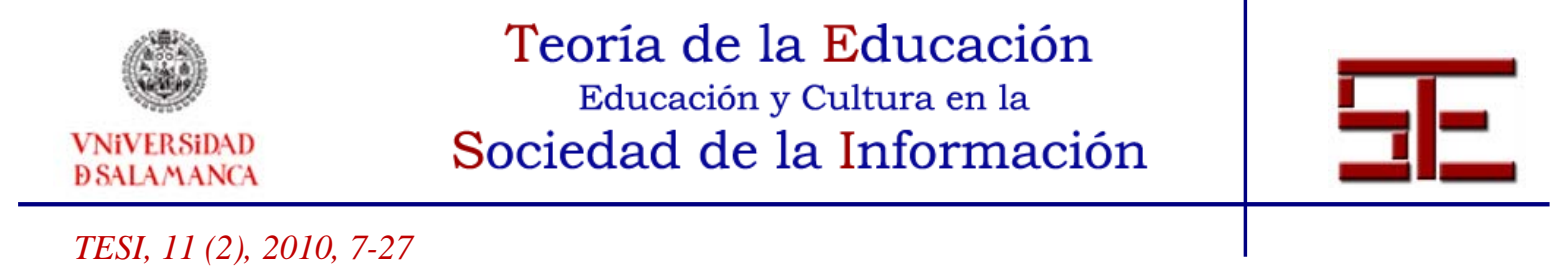

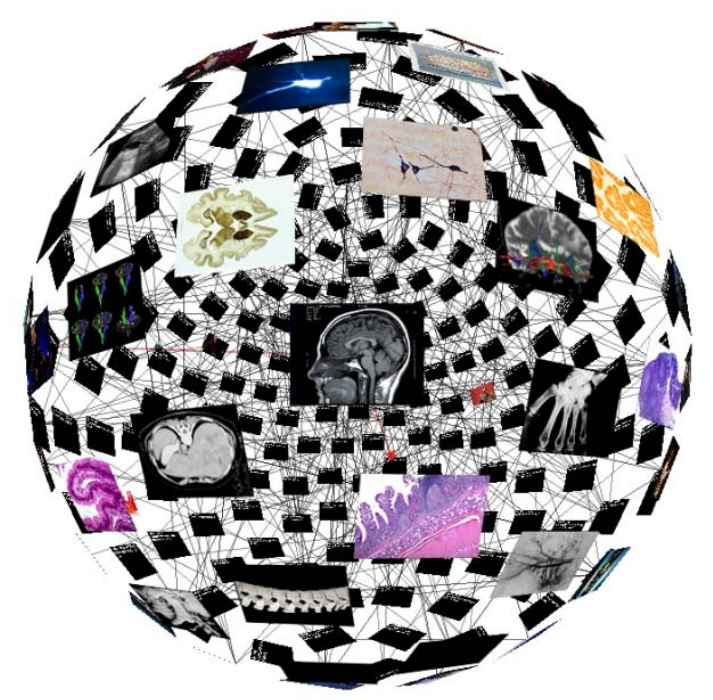

Figura 7.- Visualización de la información mediante una esfera $3 D$ giratoria que permite navegar por las diferentes imágenes o videos biomédicos y visualizar las distintas relaciones semánticas entre ellos. Este modelo de visualización potencia la capacidad relacional de las imágenes, presentándolas de modo espectacular e insertándolas en un universo visual que hace más cómodo el trabajo de los usuarios y fomentando la intuición del análisis de los datos.

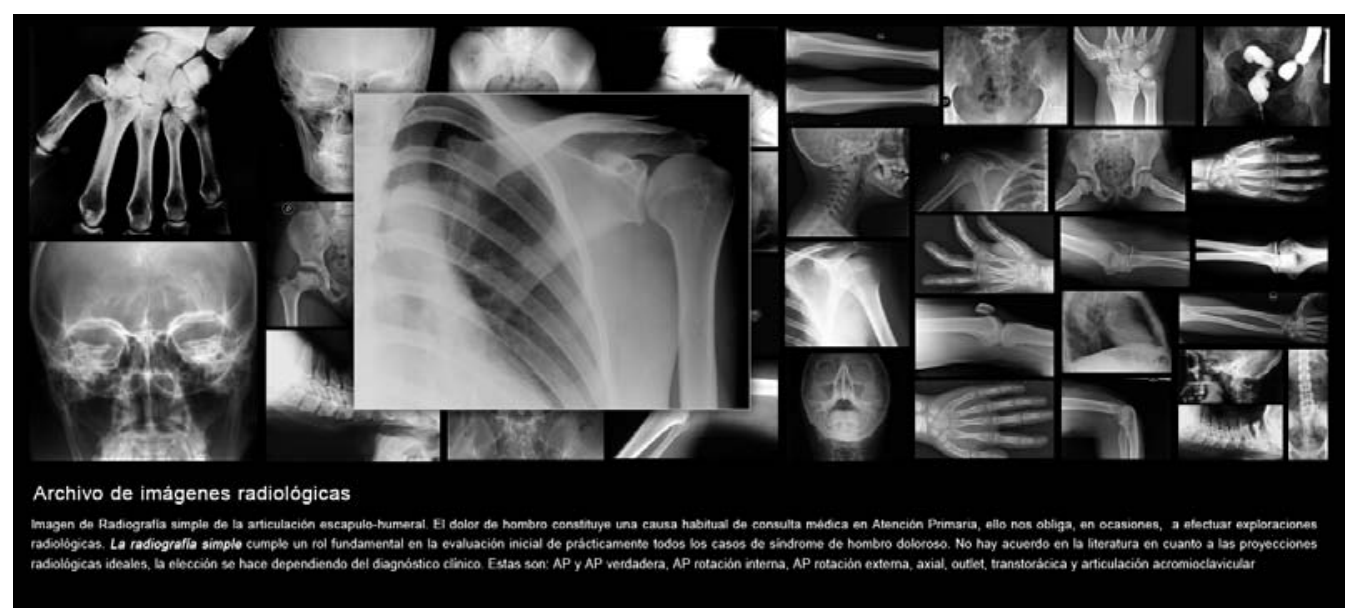

Figura 8.- Representación de un archivo de imágenes radiológicas, mediante visión planar, que permite acceder a cada una de las imágenes con un clic para su ampliación y estudio en detalle.

El aprendizaje con estos mapas conceptuales será significativo si los contenidos docentes presentados se relacionan de modo sustancial, es decir, cuando la información a transmitir logra conectar con un concepto relevante en la estructura cognitiva del

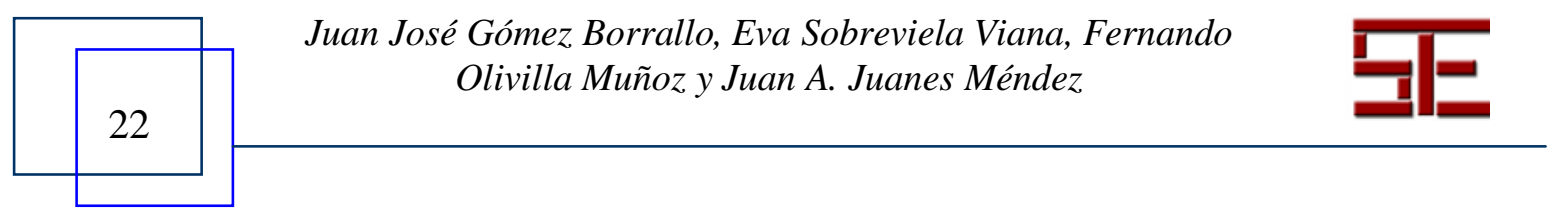




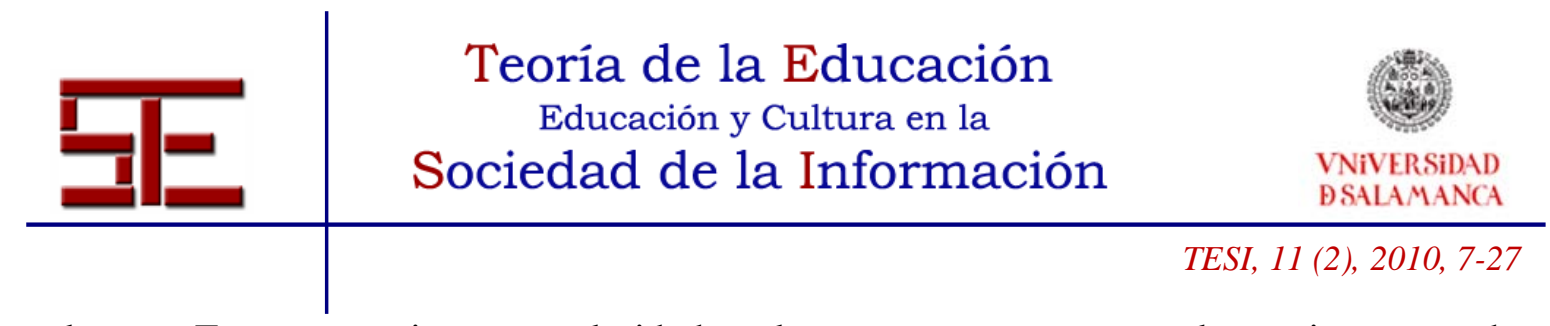

alumno. Esto se consigue con claridad en los conceptos, y con un lenguaje expresado adecuadamente, para que interactúe eficazmente con el conocimiento (Pichardo, 1999).

\section{6.- PIZARRA DIGITAL INTERACTIVA}

La incorporación de métodos de innovación docente, como las pizarras digitales interactivas (PDI), supone cambios en los roles tanto del profesor como del alumno, así como en la forma de trabajo. Estas pizarras son unos excelentes medios tecnológicos que permiten hacer visualizaciones dinámicas con participación activa de los usuarios (estudiantes), pudiendo estos observar, manipular y entender el funcionamiento de situaciones reales a través de la imagen digital.

Su funcionalidad consiste en proyectar, sobre una pantalla situada en un lugar relevante del aula o la sala, información procedente del ordenador, o de cualquier otro dispositivo analógico o digital conectado al sistema. De esta forma, profesores y alumnos tienen constantemente a su disposición un sistema para visualizar y comentar, de manera colectiva, un mundo de información en cualquier tipo de formato.

Si la pizarra cuenta además con un tablero interactivo se denomina pizarra digital interactiva o PDI. Las PDI permiten escribir directamente sobre ellas y controlar los programas informáticos con un puntero o, simplemente, con la presión de un dedo (Fig. 9).

Las PDI compensan su mayor coste con una serie de importantes ventajas.

-Permiten escribir y dibujar desde el ordenador

-Permiten el almacenamiento de las clases realizadas en un día. Se guardan las distintas "pizarras" con todas sus anotaciones.

-Posibilitan la visualización de múltiples formatos de información multimedia.

-Permiten la escritura directa sobre el tablero-pizarra

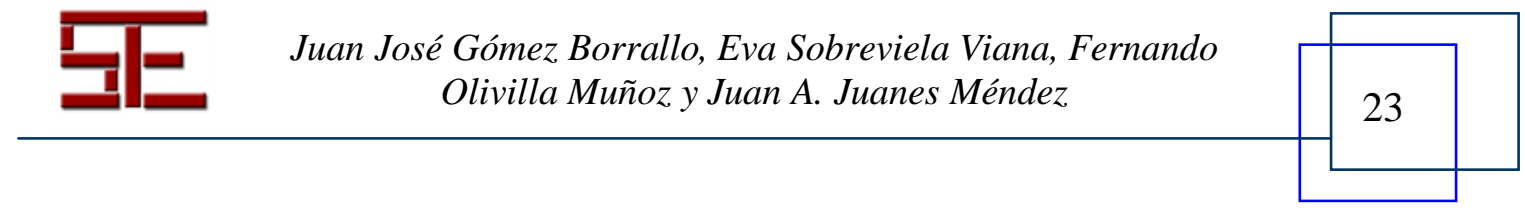



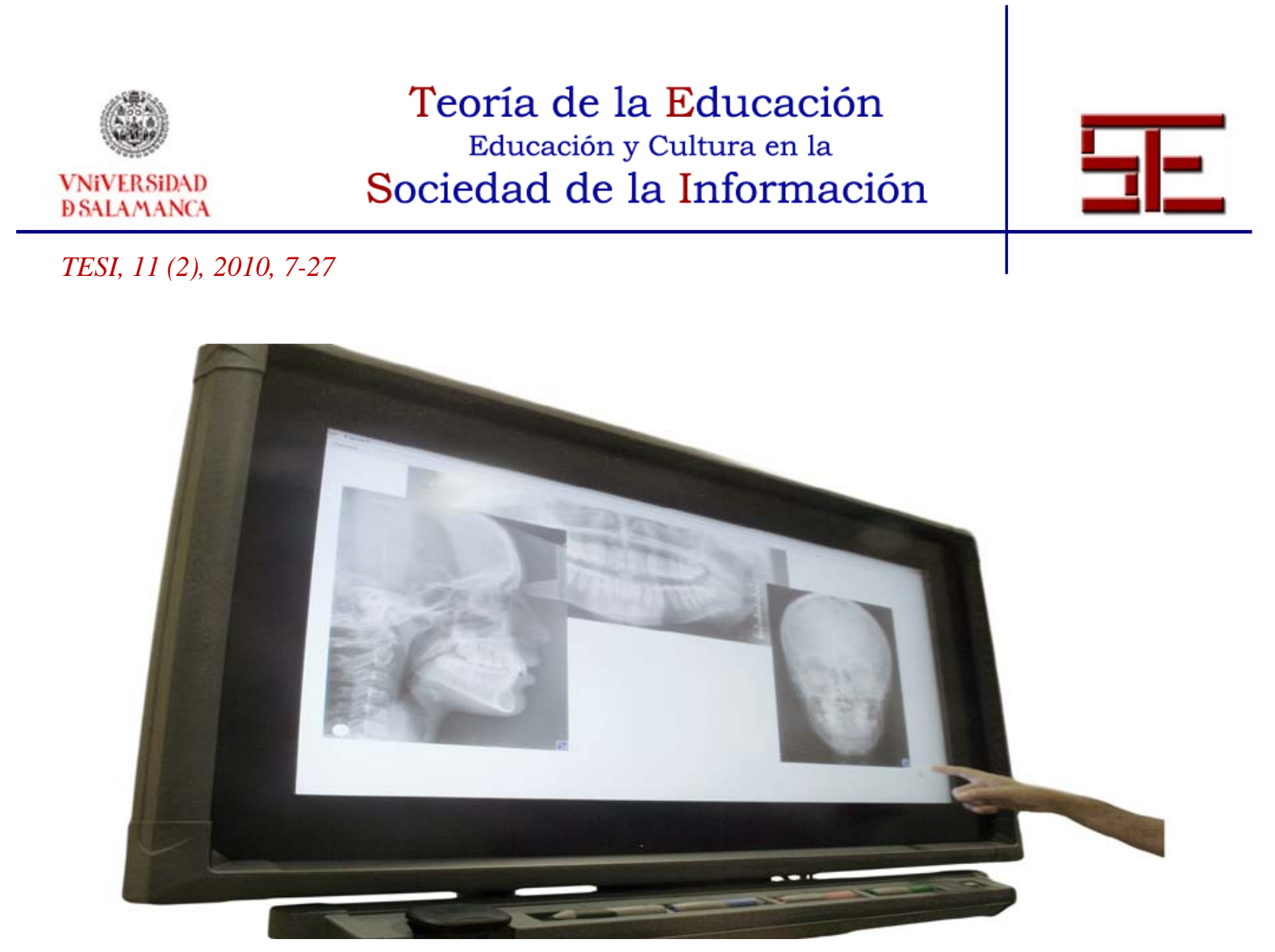

Figura 9.- Pizarra digital interactiva multipunto, modelo SmartBoard, que disponemos en nuestras instalaciones de Abadia Group. No requiere conexión a cañón de proyección. Funciona directamente conectado al ordenador. Dispone de lapiceros de cuatro colores y borrador. Su manejo se puede desarrollar directamente con las manos, ofreciendo un gran dinamismo. En la imagen se visualiza unos de los proyectos desarrollados por nuestro grupo: negatoscopio digital interactivo (NID).

La pizarra digital permite proyectar y comentar en las clases, cualquier documento o trabajo realizado por los profesores o los estudiantes. Constituye por tanto una ventana a través de la cual se pueden transmitir conceptos y emplear todos los recursos educativos que proporcionan los medios de comunicación e Internet.

Como ninguna tecnología lo había hecho antes, las PDI tienen el poder de transformar los sistemas de enseñanza y de aprendizaje. No cabe duda que el uso de las pizarras digitales interactivas multipunto acabará por imponerse en las aulas, como ya ocurrió con el retroproyector de transparencias, que desplazó en gran medida a la pizarra de tiza clásica, el proyector de diapositivas, y recientemente con el cañón de proyección.

Cada vez son más los centros universitarios que disponen de este tipo de recursos tecnológicos didácticos, y muchos estudios hablan de las ventajas que ofrecen estos medios en los procesos de enseñanza aprendizaje (Marqués, 2004; Bautista, 2005).

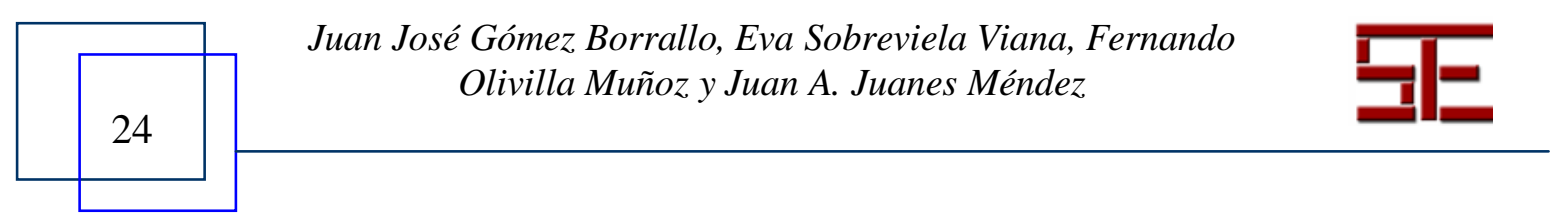




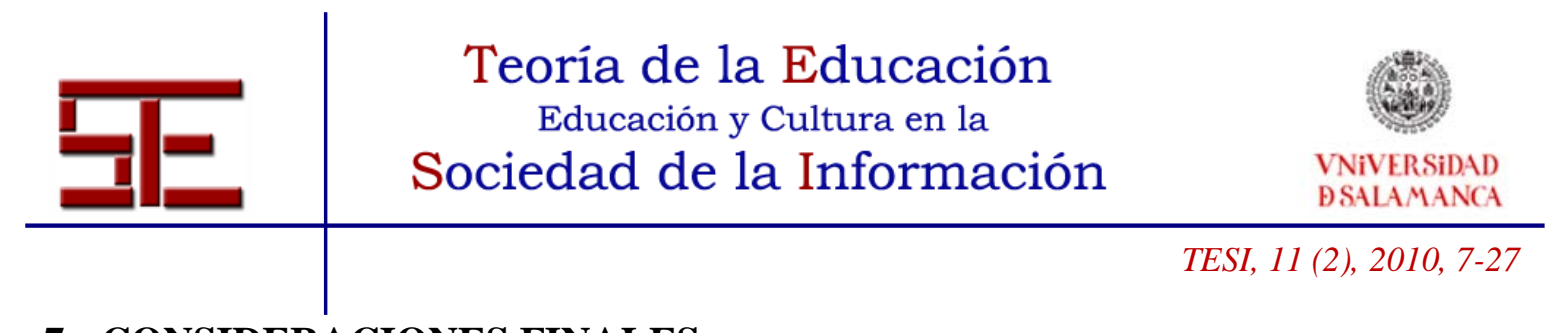

\section{7.- CONSIDERACIONES FINALES}

Los nuevos desarrollos tecnológicos, ligados a la revolución informática, están transformando las técnicas de visualización de biomédica.

La importancia de la motivación en el proceso de aprendizaje y la necesidad de la utilización de métodos tecnológicos participativos que permitan la creación de un ambiente de trabajo colectivo, ha puesto de manifiesto la necesidad de utilización y manejo de técnicas como la holográfia, los sistemas de visualización estereoscópica, etc. como medios atractivos y útiles de formación de cualquier disciplina en el área de las ciencias de la salud.

El empleo y manejo de ordenadores en cirugía se ha incrementado notablemente en los últimos años. Debido a que el uso de la imagen resulta de vital importancia en el área clínica tanto desde un punto de vista diagnóstico como terapéutico, resulta comprensible que la RA se vislumbre como una técnica de suma utilidad para planificaciones de intervenciones quirúrgicas futuras.

Los mapas conceptuales son una forma excelente de representar la información de los contenidos docentes, la cual se puede relacionar con conceptos a través de palabrasenlace, imágenes, etc... confiriéndoles un poder didáctico importante, llevando así, al estudiante, hacia una mejor comprensión de los conocimientos de aprendizaje.

La utilización de los mapas conceptuales en las ciencias de la salud es, sin duda, creciente. Esta progresiva utilización de los mapas en la enseñanza y el aprendizaje de la Medicina, la Odontología, la Enfermería, la Fisioterapia, la Terapia ocupacional, etc. tiene su origen en la capacidad que poseen los mapas conceptuales para estimular, el aprendizaje significativo.

Las PDI resultan útiles en todas las materias biosanitarias, proporcionando muchos recursos visuales y nuevas posibilidades metodológicas que facilitan la presentación y comprensión de los contenidos docentes. Las posibilidades que ofrecen la utilización de las PDI son enormes permitiéndonos innovar, motivar a los estudiantes y promover aprendizajes más significativos.

Queremos reflejar, finalmente, que la utilización de métodos tecnológicos para la formación y visualización del conocimiento, y la exploración de sus posibilidades didácticas, es ámbito de nuestra responsabilidad docente, siendo un continuo reto al que debemos enfrentarnos, tanto los profesionales vinculados al mundo educativo $\mathrm{y}$

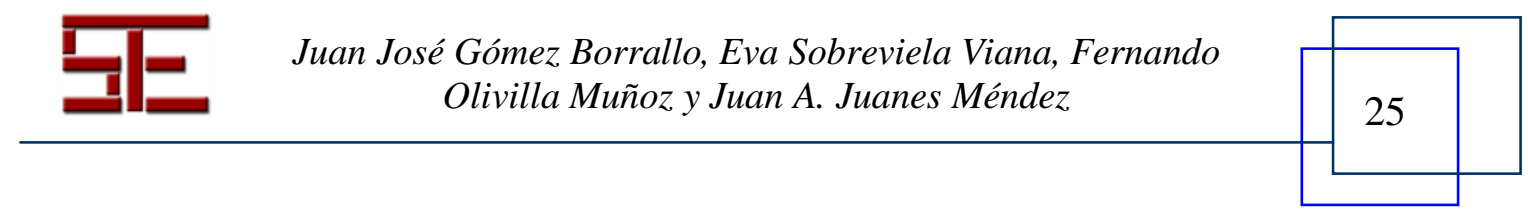




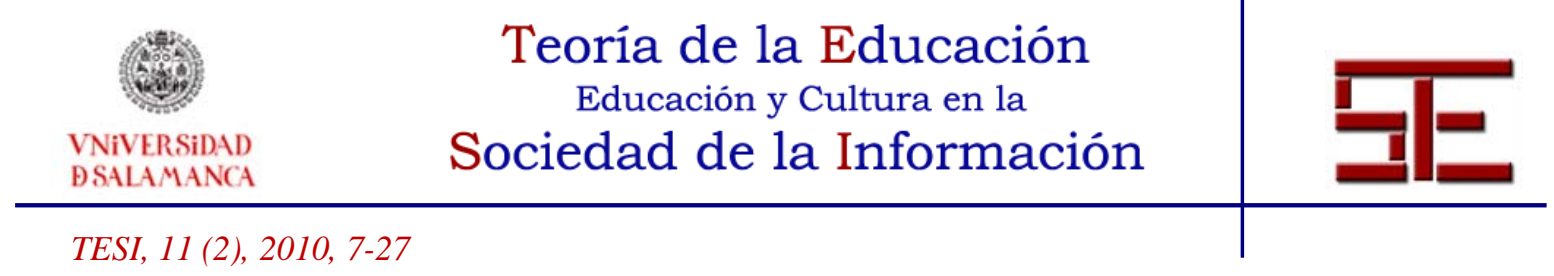

sanitario, como los encargados de elaborar y desarrollar aplicaciones tecnológicas informáticas para una optimización del aprendizaje.

\section{8.- BIBLIOGRAFÍA}

Bautista Cuéllar, R.V. (2005). La pizarra digital: La enseñanza del futuro. "Investigación y Educación” No 16.

Beléndez, A. (2009). Holografía: ciencia, arte y tecnología. Revista Brasileira de Ensino de Física, v. 31, n. 1, 1602.

http://www.scielo.br/pdf/rbef/v31n1/v31n1a11.pdf (19-4-2010)

Cyganek, B. (2009). An introduction to 3D computer vision techniques and algorithms. Chichester: Wiley.

Fonseca, A P., Extremica, C L, Y Fonseca, F. (2004). Concept mapping: a strategy for meaningful learning in medical microbiology. En: Concept maps: theory, methodology technology.Proc of the first International Conference on concept mapping. Pamplona: Cañas AJ, Novak JD, Gonzalez FM (eds).

García Santiago, L. (2000). La holografía en el mundo de la documentación.

http://www.elprofesionaldelainformacion.com/contenidos/2000/abril/5.pdf (23-4-2010)

García Santiago, L. (2005). La holografía hoy. Nuevos documentos del futuro. En Quaderns digitals.net.

http://www.quadernsdigitals.net/index.php?accionMenu=hemeroteca.VisualizaArticuloI U.visualiza\&articulo_id=8619 (24-4-2010).

Gibson, J.J. (1974). La percepción del mundo visual. Buenos Aires: E. Infinito.

Hernández-Montes Y Otros (2004). Holografía digital pulsada aplicada a la detección de in-homogeneidades en materiales semisólidos.

http://www.cio.mx/1_enc_mujer/files/Extensos/Posters/O-\%2003.pdf (20-4-2010).

Howard, I. P. \& Rogers, B.J. (1995.). "Binocular Vision and Stereopsis", Oxford.University Press,

Llamas-Nistal, M. (2003). Computers and education: towards a lifelong learning society. Dordrecht : Kluwer Academic.

Lewis-Willians, D. (2005). La mente en la caverna. La conciencia y los orígenes del arte. Madrid: Akal.

Lipton, L. (1997). "Stereo-vision formats for video and computers graphics", StereoGraphics Corporation.

Martín Pascual, P. (1997). El libro de la Holografía. Madrid, Alianza.

Mirzoeff, N. (2003). Introducción a la cultura visual. Barcelona: Paidós Ibérica.

Piaget, J. (1980). Epistemología genética y equilibración. Madrid: Fundamentos DL.

Parra Marquez, J.C., García Alvarado, R., Santelices Malfani, I. (2001). "Introducción Práctica a la Realidad Virtual” Ediciones U. Bío-Bío, Concepción, (Chile).

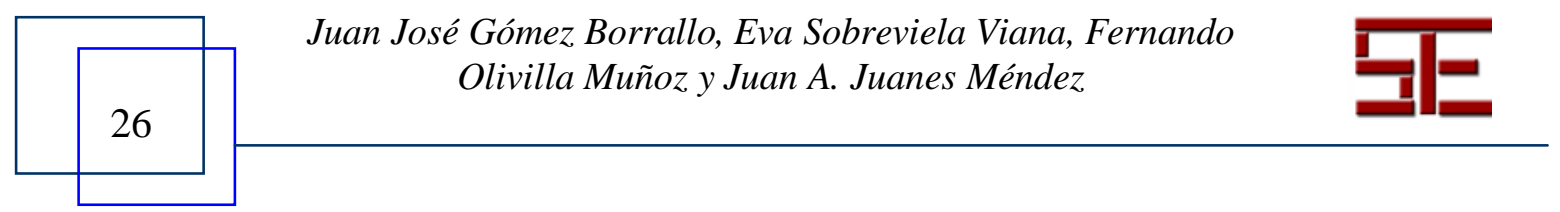




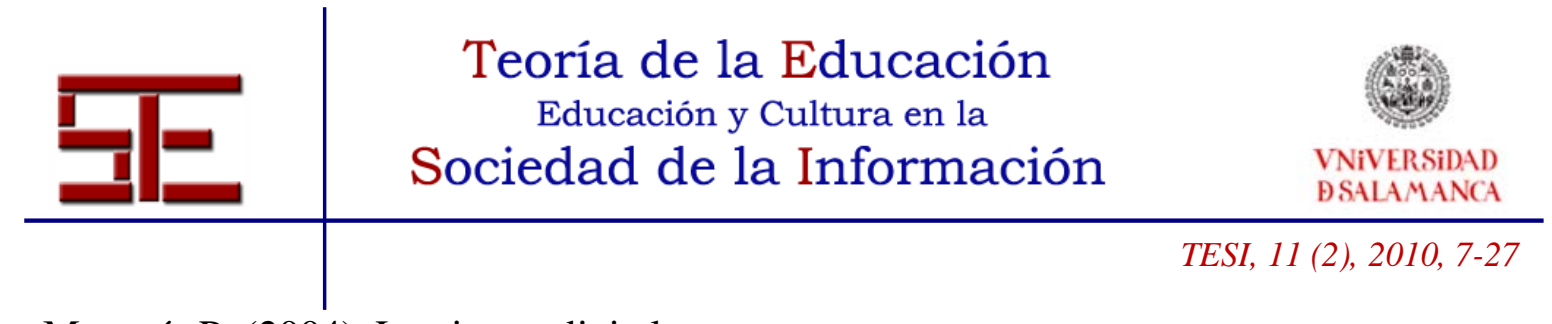

Marqués P. (2004). La pizarra digital:

http://dewey.uab.es/pmarques/pdigital/es/propuest.htm

Mayer R.E. (2005). The Cambridge handbook of multimedia learning / edited by Richard E. Mayer. Cambridge: Cambridge University Press.

Ontoria, P A. (1994). Mapas conceptuales: una técnica para aprender. Madrid: Narcea.

Pajares Martisanz, G. (2007). Visión por computador: imágenes digitales y aplicaciones. Madrid: Ra-Ma D.L.

Pichardo, J.P. (1999). Didáctica de los mapas conceptuales. Ed. Jertalhum, México.

Pons Moreno, A.M.- Martínez Verdú, F.M. (2004). Fundamentos de vision binocular. Valencia: universidad de alicante.

Smith, A (1999). Interactive whiteboard evaluation. Mirandanet.

Sánchez-Quevedo, M. C, cubero, m a, alaminos, m y campos, a. (2005). El mapa conceptual como instrumento de evaluación del aprendizaje significativo en histología y embriología bucodental. Actas del XVII Congreso de Educación Médica 2005.

Torres Ponjúan, D. (2008). Visualización de la información bases y desafíos interdisciplinares. Bibliotecología y ciencia de la información. Facultad de comunicación. Universidad de la habana. Congreso internacional de información, 2008

Visions 2002: transforming education and training through advanced technologies. U.s. department of commerce, u.s. department of education netday

Vygotskii, L.S. (1979). El desarrollo de los procesos psicológicos superiores. Barcelona: crítica.

Wöhler, CH. (2009). 3d computer vision: efficient methods and applications. Berlín: springer cop.

Para citar el presente artículo puede utilizar la siguiente referencia:

Gómez Borrallo, J.J.(2010): Nuevos avances en los sistemas de visualización y presentación de contenidos docentes, en Juanes Méndez, J.A. (Coord.) Avances tecnológicos digitales en metodologías de innovación docente en el campo de las Ciencias de la Salud en España. Revista Teoría de la Educación: Educación y Cultura en la Sociedad de la Información. Vol. 11, no 2. Universidad de Salamanca, pp. 7-27 [Fecha de consulta: $\mathrm{dd} / \mathrm{mm} / \mathrm{aaaa}]$.

http://campus.usal.es/ revistas_trabajo/index.php/revistatesi/article/view/7068/7101

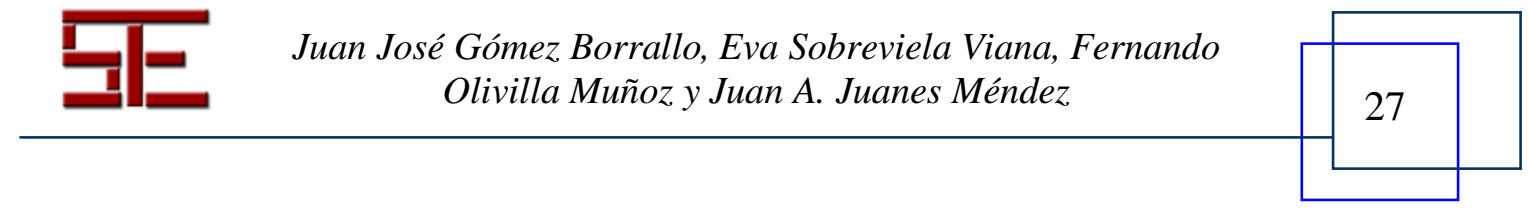

